\title{
It Is All in the Right Amygdala: Increased Synaptic Plasticity and Perineuronal Nets in Male, But Not Female, Juvenile Rat Pups after Exposure to Early-Life Stress
}

\author{
Angela Guadagno, ${ }^{1,2}$ Silvanna Verlezza, ${ }^{1}$ Hong Long, ${ }^{1}{ }^{\circledR}$ Tak Pan Wong, ${ }^{1,3}$ and ${ }^{\circledR}$ Claire-Dominique Walker ${ }^{1,3}$ \\ ${ }^{1}$ Douglas Mental Health University Institute, Montreal, Quebec, H4H 1R3, Canada, ${ }^{2}$ Integrated Program in Neuroscience, McGill University, \\ Montreal, Quebec, H3A 0G4, Canada, and ${ }^{3}$ Department of Psychiatry, McGill University, Montreal, Quebec, H3A 0G4, Canada
}

Early-life stress (ELS) is associated with increased vulnerability to mental disorders. The basolateral amygdala (BLA) plays a critical role in fear conditioning and is extremely sensitive to ELS. Using a naturalistic rodent model of ELS, the limited bedding paradigm (LB) between postnatal days 1-10, we previously documented that LB male, but not female preweaning rat pups display increased BLA neuron spine density paralleled with enhanced evoked synaptic responses and altered BLA functional connectivity. Since ELS effects are often sexually dimorphic and amygdala processes exhibit hemispheric asymmetry, we investigated changes in synaptic plasticity and neuronal excitability of BLA neurons in vitro in the left and right amygdala of postnatal days 22-28 male and female offspring from normal bedding or LB mothers. We report that LB conditions enhanced synaptic plasticity in the right, but not the left BLA of males exclusively. LB males also showed increased perineuronal net density, particularly around parvalbumin $(\mathrm{PV})$ cells, and impaired fear-induced activity of PV interneurons only in the right BLA. Action potentials fired from right BLA neurons of LB females displayed slower maximal depolarization rates and decreased amplitudes compared with normal bedding females, concomitant with reduced NMDAR GluN1 subunit expression in the right BLA. In LB males, reduced GluA2 expression in the right BLA might contribute to the enhanced LTP. These findings suggest that LB differentially programs synaptic plasticity and PV/perineuronal net development in the left and right BLA. Furthermore, our study demonstrates that the effects of ELS exposure on BLA synaptic function are sexually dimorphic and possibly recruiting different mechanisms.

Key words: amygdala; early life stress; juvenile; LTP; perineuronal net; sex

Significance Statement

Early-life stress (ELS) induces long-lasting consequences on stress responses and emotional regulation in humans, increasing vulnerability to the development of psychopathologies. The effects of ELS in a number of brain regions, including the amygdala, are often sexually dimorphic, and have been reproduced using the rodent limited bedding paradigm of early adversity. The present study examines sex differences in synaptic plasticity and cellular activation occurring in the developing left and right amygdala after limited bedding exposure, a phenomenon that could shape long-term emotional behavioral outcomes. Studying how ELS selectively produces effects in one amygdala hemisphere during a critical period of brain development could guide further investigation into sex-dependent mechanisms and allow for more targeted and improved treatment of stress-and emotionality-related disorders.

Received Apr. 26, 2020; revised Sep. 13, 2020; accepted Sep. 16, 2020.

Author contributions: A.G. and C.-D.W. designed research; A.G., S.V., H.L., and C.-D.W. performed research; A.G. analyzed data; A.G. wrote the first draft of the paper; A.G., T.P.W., and C.-D.W. edited the paper; A.G. and C.-D.W. wrote the paper.

This work was supported by Canadian Institutes for Health Research Grant PJT162376 to C.-D.W. and Natural Sciences and Engineering Research Council PGSD award to A.G. The present study used the services of the Molecular and Cellular Microscopy Platform at the Douglas Institute Research Center. We thank Alyssa Guerra, Alice Wong, and Moushumi Nath for help with these experiments.

The authors declare no competing financial interests.

Correspondence should be addressed to Claire-Dominique Walker at Dominique.walker@douglas.mcgill.ca. https://doi.org/10.1523/JNEUROSCI.1029-20.2020

Copyright $\odot 2020$ the authors

\section{Introduction}

Early-life stress (ELS) exposure has long-term consequences on cognitive and emotional health (Bolton et al., 2017; Krugers et al., 2017). The basolateral amygdala (BLA) is crucial in the acquisition and expression of conditioned fear (Pape and Pare, 2010) and undergoes persistent changes in response to ELS (Malter Cohen et al., 2013). We previously reported that ELS increases spine density in excitatory BLA neurons and evoked synaptic responses in male preweaning rats (Guadagno et al., 2018a). Sex impacts of ELS are observed in the developing BLA and associate with heightened anxiety-like and fear behaviors in adult males, 
but not females (Guadagno et al., 2018a). Sex-specific and agedependent effects of ELS have also been documented in the PFC and hippocampus (Walker et al., 2017; Goodwill et al., 2019), possibly reflecting a differential time course of brain development (Lenroot et al., 2007) and different windows of vulnerability (Derks et al., 2016).

Precisely how ELS leads to sex-dependent functional and cellular alterations in the BLA remains elusive. High-frequency stimulation of lateral amygdala (LA) inputs to the developing BLA induces modest LTP on postnatal day 7 (PND7) to PND10 (Thompson et al., 2008) and successful LTP on PND20 in both sexes (Bender et al., 2017). Hyperexcitability in BLA pyramidal neurons and enhanced anxiety-like behavior are observed in adolescent (PND28-PND32) male rats (Hetzel and Rosenkranz, 2014), but it is still unclear whether ELS can modify LTP in juveniles. Our studies were designed to examine sex- and hemispheric-dependent effects of ELS on synaptic plasticity in the juvenile BLA. In adulthood, chronic stress increases LTP formation in the BLA, which elicits the long-term consolidation of fear memories in male rats (Suvrathan et al., 2014). Activation of developmentally regulated glutamatergic NMDARs (Lopez de Armentia and Sah, 2003) critically mediates changes in synaptic plasticity and fear learning (Dalton et al., 2012; Miller et al., 2020). All three major NMDAR subunits (GluN1, GluN2A, and GluN2B) are expressed in the juvenile BLA (Delaney et al., 2013), but the effect of ELS on their expression and contribution to synaptic plasticity at this age are unknown. Similarly, AMPAR subunits (GluA1, GluA2) that mainly control synaptic strength during synaptic plasticity (Diering and Huganir, 2018) are modulated by corticosterone in the neonatal amygdala (Opendak et al., 2018), suggesting that ELS might also impact these glutamate receptor subunits. Interestingly, adult BLA function exhibits hemispheric asymmetry in humans and rodents, with the right amygdala being more heavily involved in fear and pain processing than the left (Baker and Kim, 2004; Ji and Neugebauer, 2009). Based on our observation that lateralization of the amygdala is already observed preweaning, with more resting-state fMRI connectivity changes found in the right versus the left BLA in males exposed to ELS (Guadagno et al., 2018b), we tested the hypothesis that juvenile synaptic plasticity in the right amygdala is also more affected by ELS than in the left BLA.

In adults rodents, glutamatergic synaptic output of BLA pyramidal cells is directly modulated by inhibitory GABAergic interneurons expressing the calcium-binding protein parvalbumin (PV) (Berdel and Moryś, 2000). PV cells form approximately half of the interneurons in the adult BLA (Woodruff and Sah, 2007b), display hemispheric asymmetry in numbers (Butler et al., 2018), and mature between PND14 and PND30 (Berdel and Moryś, 2000). PV interneurons in the BLA are encapsulated by proteoglycan-rich specializations of the extracellular matrix called perineuronal nets (PNNs) that reach adult levels by PND28 (Gogolla et al., 2009). The formation of PNN around PV neurons coincides with and likely contributes to the closure of critical periods of cortical synaptic plasticity (Takesian and Hensch, 2013), making these components important regulators of PV activity. A recent study using a restricted model of early life adversity found that PNN staining in the BLA of PND23 rats was reduced (Santiago et al., 2018), suggesting that PNNs in the developing BLA are sensitive to the early environment. Here, we examined how ELS modifies inhibitory neuron populations of the BLA and whether early maturation of PNNs associates with BLA hyperexcitability in juveniles. We hypothesized that increased BLA synaptic plasticity and neuron excitability in early stressed juvenile males would be associated with accelerated development of PNNs around PV interneurons and reduced PV inhibitory activity.

\section{Materials and Methods}

Animals. Untimed-pregnant (received on gestation day 16-17) Sprague Dawley female rats (Charles River) were individually housed under controlled conditions of light (reverse $12 \mathrm{~h}$ light: $12 \mathrm{~h}$ dark, lights off at $08: 00 \mathrm{~h})$, temperature $\left(22^{\circ} \mathrm{C}-24^{\circ} \mathrm{C}\right)$, and humidity $(70 \%-80 \%)$ and provided ad libitum access to rat chow and water. The day of parturition was considered PND0, and litters were culled to 10 pups on PND1 with 5 males and 5 females if possible. Animals were weaned on PND22 and same-sex group-housed with environmental enrichment until death on PND22-PND29. All experimental procedures were approved by the University Animal Care Committee at McGill University in accordance with the guidelines of the Canadian Council on Animal Care.

Limited bedding paradigm. Early chronic stress in the offspring was induced using the limited bedding (LB) and nesting protocol adapted from Baram and colleagues (Molet et al., 2014; Walker et al., 2017), which causes disruptions of maternal care as previously validated in our laboratory (McLaughlin et al., 2016; Guadagno et al., 2018a). A total of four cohorts of dams (total of 22 dams and their litters) provided offspring for different sets of experiments. Cohort 1 dams ( 2 or 3/bedding condition) were used for the LTP and input-output experiments. Cohort 2 dams ( 3 or 4/bedding condition) were used for the whole-cell recording experiments. Cohort 3 dams (3/bedding condition) were used for the Western blot experiments, and Cohort 4 dams (2/bedding condition) contributed to the fear conditioning and immunohistochemistry experiments. On PND1, mothers and their litters were randomly assigned to the LB or normal bedding (NB) condition. LB mothers and their litters were placed on a wire mesh platform elevated $2.5 \mathrm{~cm}$ above the cage floor, with $\sim 1.5 \mathrm{~cm}$ of bedding underneath. Nesting material consisted of one-half of one paper towel. NB cages were given a $2.5 \mathrm{~cm}$ layer of woodchips and one-half of one paper towel. Cages were changed on PND4; and on PND10, all LB mothers/litters were returned to the normal bedding conditions. Dams and litters were weighed on PND1, PND4, PND10, and PND22. All litters remained with their biological mother until weaning on PND22. Pups were also weighed on PND28 when possible. Although early postnatal stress using the LB paradigm was the main stressor examined on the offspring, we also acknowledge that transport of the pregnant mothers to the animal facility might have enhanced the observed effects of the LB procedure (Moriyama et al., 2013; Bonapersona et al., 2019).

Slice preparation for field and whole-cell recordings. NB and LB animals aged PND22-PND28 were used for field recordings ( $n=5-8$ pups/ group and sex from $n=2$ or 3 mothers/group) and PND25-PND28 for whole-cell recordings ( $n=5$ or 6 pups/group and sex from $n=3$ or 4 mothers/group). We and others have successfully recorded fEPSP responses in the BLA at these early ages (Aroniadou-Anderjaska et al., 2001; Guadagno et al., 2018a). Juvenile rats were anesthetized with isoflurane before being decapitated. The brains were rapidly removed, marked with a blade on the top-right side, and coronal slices $(250 \mu \mathrm{m})$ containing the amygdala were cut using a Vibratome (Leica Microsystems) in hyperosmotic, ice-cold carbogenated $\left(95 \% \mathrm{O}_{2} / 5 \% \mathrm{CO}_{2}\right)$ sucrose-substituted aCSF containing the following (in mM): 252 sucrose, $2.5 \mathrm{KCl}, 0.1 \mathrm{CaCl}_{2}, 4$ $\mathrm{MgCl}_{2}, 10$ glucose, $26 \mathrm{NaHCO}_{3}$, and $1.25 \mathrm{NaH}_{2} \mathrm{PO}_{4}, \mathrm{pH} 7.35$ (360-370 mOsm). Slices were then incubated in carbogenated normal aCSF (125 $\mathrm{mm} \mathrm{NaCl}$ in place of sucrose; $310-320 \mathrm{mOsm}$ ) at $32^{\circ} \mathrm{C}$ for $1 \mathrm{~h}$ and subsequently kept at room temperature for a minimum of $1 \mathrm{~h}$ before recording onset. All recordings were amplified by MultiClamp 700B and stored in a PC for offline analysis using Clampfit (Axon, Molecular Devices).

Field and whole-cell recordings. The protocols for slice recording were described previously (Guadagno et al., 2018a). Bicuculline (5 $\mu \mathrm{M})$, a $\mathrm{GABA}_{\mathrm{A}}$ receptor antagonist, was added in the perfusing solution during fEPSP recordings. Evoked fEPSPs were induced by a bipolar stimulating electrode that was placed in the LA, adjacent to the BLA and recorded by an aCSF-filled glass electrode. LTP was induced by two $1 \mathrm{~s}$ 

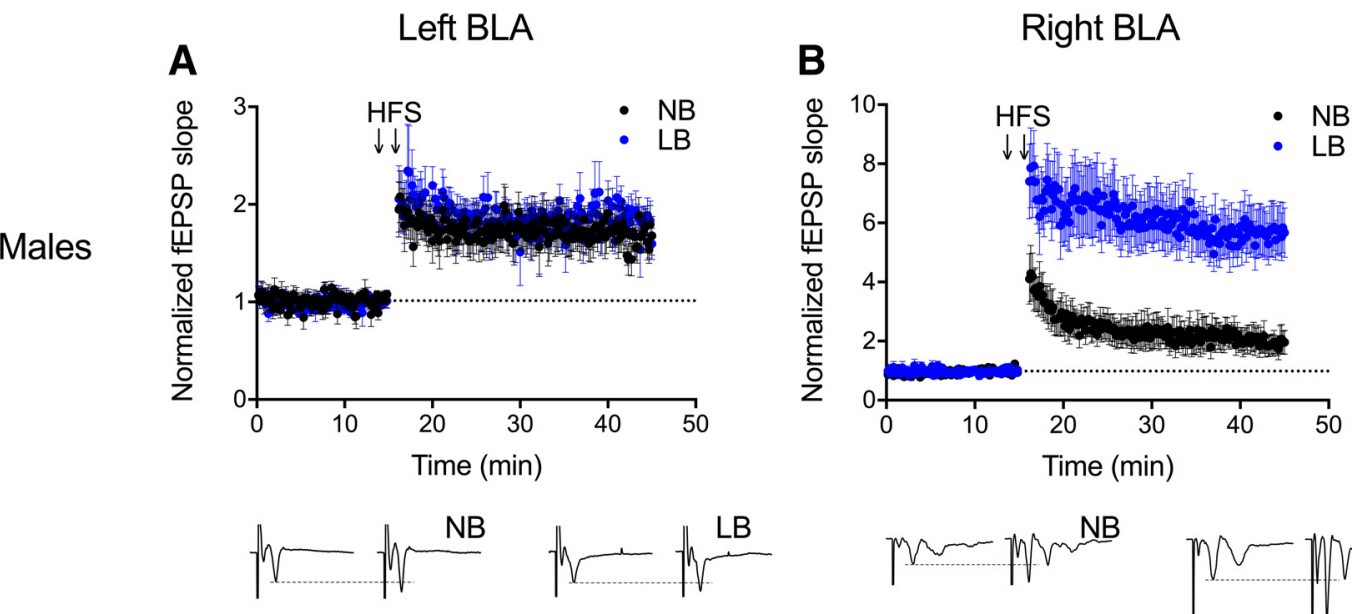

Males
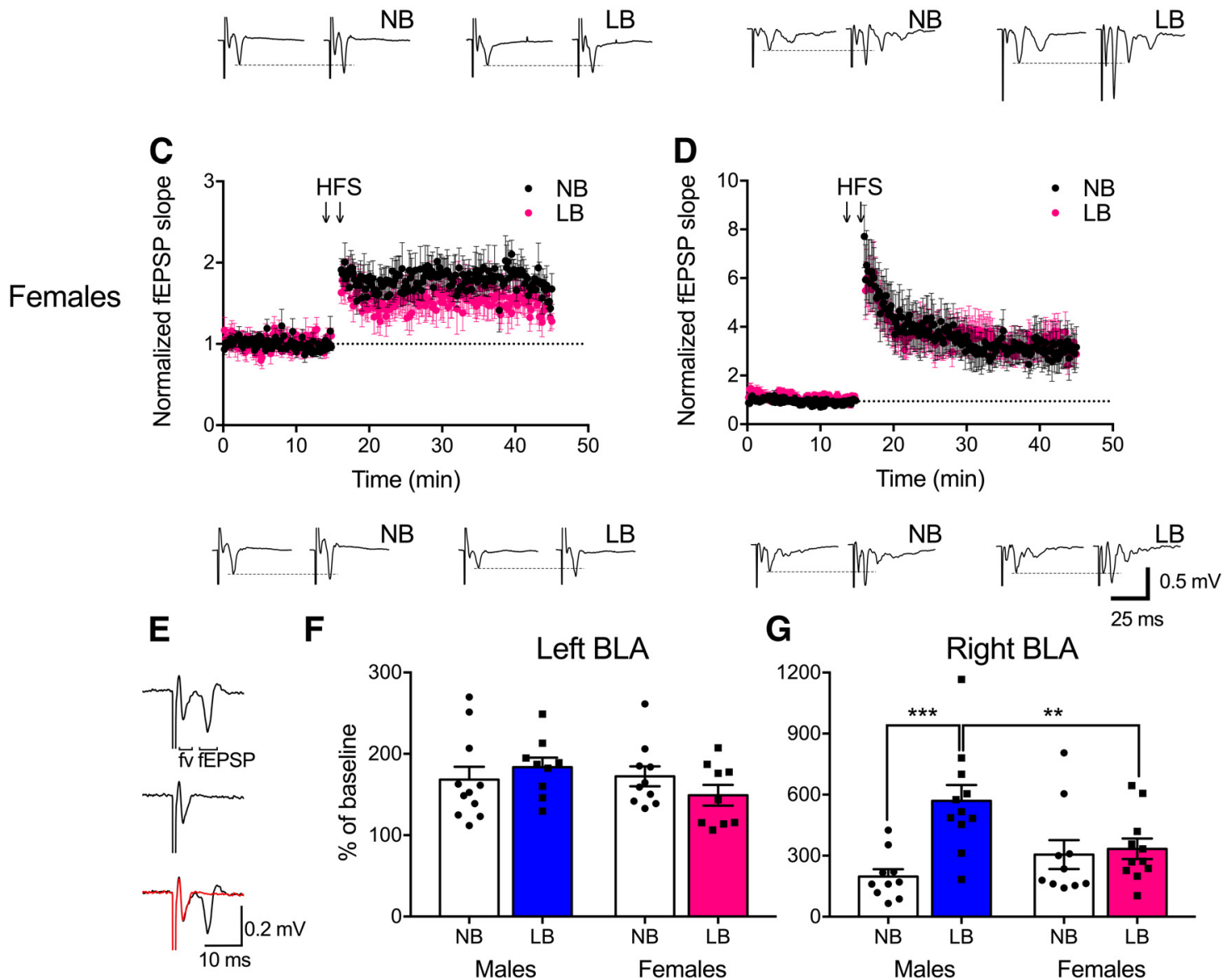

Figure 1. LTP in the left and right BLA of PND22-PND28 animals. Plots of evoked fEPSP slope against time are normalized to baseline for each recording. Representative traces below each plot were obtained 2 min before (left traces) and 25 min after HFS (right traces). $\boldsymbol{A}, \boldsymbol{B}$, In males, LB enhanced LTP in the right BLA only. $\boldsymbol{C}, \boldsymbol{D}$, There was no effect of LB-rearing on LTP formation in females in either the left or right BLA. $E$, Representative trace of evoked fEPSP before (top) and after the blockade of AMPARs by DNQX (middle). This trace is overlapped in the bottom. Red represents after DNQX treatment. Fiber volley (fv) of the trace was insensitive to the DNQX blockade. $\boldsymbol{F}, \boldsymbol{G}$, LTP as a function of percent of baseline in NB or LB male and female groups in the right and left BLA 25-30 min after HFS. LB male pups displayed significantly enhanced LTP compared with NB males and LB females in the right BLA only. Two-way ANOVAs with bedding and sex as between-subject factors were performed and followed by simple effects tests to decompose significant interactions. Data are mean \pm SEM of $n=9-11$ slices/group, 5-8 animals/group. ${ }^{* *} p<0.01$. ${ }^{* *} p<0.001$.

applications of high-frequency stimulation (HFS; $100 \mathrm{~Hz}, 100$ pulses), separated by $20 \mathrm{~s}$. The stimulus intensity for LTP experiments was adjusted to evoke a field potential of an amplitude $40 \%$ of the maximum fEPSP response. LTP of fEPSP slope was estimated at 25-30 min after HFS. Input-output recordings were performed on separate slices from those used for LTP induction. The magnitude of fiber volleys in the right BLA of male and female juveniles was also estimated at 25-30 min after tetanus to determine whether presynaptic mechanisms could contribute to increased LTP after LB exposure. To correctly identify the fiber volley as the first negative deflection in electrophysiological traces, we performed control recordings in the right BLA ( $n=4$ slices from 3 females and 1 male PND25-PND27, 1 NB litter) using bicuculline (5 $\mu \mathrm{M})$ in the perfusing solution followed by DNQX $(10 \mu \mathrm{M})$, an AMPAR antagonist. Trace components identified as fiber volleys, but not fEPSPs, were indeed insensitive to DNQX treatment (see Fig. 1E).

Spiking properties were recorded in the whole-cell patch-clamp mode in BLA neurons with pipettes containing the following (in $\mathrm{mM}$ ): $120 \mathrm{~K}$-gluconate, $17.5 \mathrm{KCl}, 2 \mathrm{MgCl}_{2}, 0.5$ EGTA, $10 \mathrm{HEPES}, 4 \mathrm{Na}_{2}$-ATP, and with the $\mathrm{pH}$ adjusted to 7.2 with $\mathrm{KOH}(\sim 290 \mathrm{mOsm})$. Neurons recorded in current-clamp mode were injected with 1000-ms-long depolarizing current pulses in increasing steps of $10 \mathrm{pA}$ to evoke action potentials ( 20 sweeps total, $10 \mathrm{~s}$ per sweep). The average action potential amplitude and total number of action potentials were calculated from all spikes obtained over 20 sweeps. The action potential threshold and 
maximal depolarization rate were determined from the first spike induced. The voltage at which point the $d V / d t$ trace first passed $10 \mathrm{mV} /$ $\mathrm{ms}$ was considered to be the threshold. Only recordings with stable and low access resistance $<15 \mathrm{~m} \Omega$ were used. Only recordings from neurons showing clear spike adaptation and after hyperpolarization patterns similar to BLA pyramidal neurons were kept for analyses, since those fastspiking neurons that show little spike adaptation are normally resembling the properties of inhibitory interneurons (Woodruff and Sah, 2007a; Ehrlich et al., 2012).

NMDAR and AMPAR subunit protein expression by Western blotting. NMDARs are developmentally regulated and critical for synaptic plasticity in the BLA (Muller et al., 2009; Suvrathan et al., 2014). Thus, we examined BLA expression of the three major NMDAR subunits: GluN1, GluN2A, and GluN2B (Delaney et al., 2013). We also determined the major AMPAR subunits, GluA1 and GluA2, in these experiments. Tissue punches ( $1 \mathrm{~mm}$ diameter per side) from PND28 male and female animals ( $n=5$ or 6 pups/group, from 3 mothers/group) were collected from fresh tissue, frozen on dry ice, and later sonicated for $30 \mathrm{~s}$ and homogenized in $1 \times$ RIPA buffer (\#9806, Cell Signaling Technology) with 2 mM PMSF (P7626, Sigma Millipore). Samples were centrifuged at $13,000 \mathrm{rpm}$ for $30 \mathrm{~min}$ at $4^{\circ} \mathrm{C}$. The pellet was discarded, and protein concentration in the supernatant was determined by the Bradford protein assay. A quantity of $30 \mu \mathrm{g}$ (GluN1, GluN2B, GluA1, GluA2) and $40 \mu \mathrm{g}$ (GluN2A) of lysate was diluted in $2 \times$ Laemmli sample buffer (Bio-Rad), heated at $95^{\circ} \mathrm{C}$ for $5 \mathrm{~min}$ to denature proteins, and then separated on a $8 \%$ Tris-glycine gel at $110 \mathrm{~V}$ for $12 \mathrm{~min}$ and $160 \mathrm{~V}$ for $50 \mathrm{~min}$ in Tris-glycine running buffer $(\mathrm{pH} 8.3,25 \mathrm{~mm}$ Tris base, $192 \mathrm{~mm}$ glycine, $0.1 \%$ SDS), and transferred onto nitrocellulose membranes $(0.45 \mu \mathrm{m}$, Hybond-C Extra, RPN203E, GE Healthcare) at $0.22 \mathrm{~A}$ (2 gels) for $2 \mathrm{~h}$ on

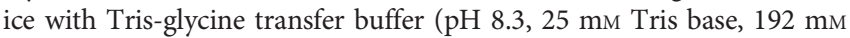
glycine, $20 \%$ methanol). The membranes were left to air dry for $15 \mathrm{~min}$, cut into two pieces according to the protein band size, and washed 3 $\times 5$ min in $1 \times$ TBST $(1 \times$ Tris buffered saline with $0.1 \%$ Tween-20). The cut blots were incubated in a blocking solution for $90 \mathrm{~min}(1 \times \mathrm{TBST}$ and $5 \%$ nonfat dry milk) and then incubated separately overnight at $4^{\circ} \mathrm{C}$ with the appropriate primary antibody: GluN1 (G8913, Sigma Millipore, 1:1000), GluN2A (\#4205, Cell Signaling Technology, 1:1000), GluN2B (NB300-106, Novus Biologicals, 1:1000), GluA1 (AB1504, Millipore, 1:500), GluA2 (MAB397, 1:1000), and actin (A2066, Sigma Millipore, 1:1000). The next day, the blots were washed in $1 \times$ TBST buffer, then incubated for $60 \mathrm{~min}$ at room temperature with the secondary antibody, either goat anti-rabbit IgG HRP (HAF008, Novus Biologicals, 1:1000 for NMDAR and GluA1) or anti-mouse IgG HRP for GluA2 (SC-2005, Santa Cruz Biotechnology, 1:1000). Gel loading of the samples was designed to test the effects of bedding and side (3 NB and 3 LB samples, each for both left and right BLA) within the same gel. Samples originating from male and female offspring were run on separate gels. The blots were developed using Clarity Western ECL Substrate (Bio-Rad) and visualized with the ChemiDoc XRS + System (Bio-Rad). Band intensity was analyzed using ImageJ (National Institutes of Health). Optical density measurements were normalized using actin to control for the amount of protein loaded on the gel and using an internal control sample run in each gel to control for intergel variability.

Fear conditioning. All fear tests were performed in the dark under red light between 09:30 $\mathrm{h}$ and 15:30 h, and rats were given at least $30 \mathrm{~min}$ to acclimatize to the experimental room before the onset of testing. The fear chamber was cleaned with Peroxyguard between trials. Male and female offspring from NB and LB mothers were separated into fear testing or control groups ( $n=5$ pups/condition and sex from $n=2$ mothers/group) on PND28-PND29. Fear group animals were placed in an operant chamber with floor metal rods for shock delivery. Rats were habituated to this environment for $5 \mathrm{~min}$, then exposed to two habituation $80 \mathrm{~dB}$ tones alone, followed by six tone-shock pairings $(1 \mathrm{~s} 0.6 \mathrm{~mA}$ shock, coterminating with $30 \mathrm{~s} 80 \mathrm{~dB}$ tone, average of 2 min variable intertrial interval). Control animals were placed in the boxes for the same total duration as the fear animals but were not exposed to the tones or shock. At the end of testing, animals were weighed and then individually housed and perfused $60 \mathrm{~min}$ after the onset of testing. Freezing behavior was manually scored by an experimenter blind to treatment conditions and converted to percentage of freezing time during the $30 \mathrm{~s}$ tone. Freezing was defined as the absence of movement, except for respiration, providing the animal was awake (Stevenson et al., 2009).

Brain collection for immunohistochemistry. Following fear conditioning, animals were anesthetized with a cocktail of ketamine/xylazine $(0.1 \mathrm{ml} / 100 \mathrm{~g}$ body weight, s.c. injection) and transcardially perfused with $0.9 \%$ ice-cold saline for $5 \mathrm{~min}$, followed by a $15 \mathrm{~min}$ perfusion with $4 \%$ PFA. The brains were extracted and stored in $4 \%$ PFA overnight, then transferred to a $30 \%$ sucrose solution in $1 \times$ PBS for $48 \mathrm{~h}$ at $4^{\circ} \mathrm{C}$. The right side of the brains was marked using a blade, and brains were stored at $-80^{\circ} \mathrm{C}$ until sectioning. Free-floating coronal sections of $50 \mu \mathrm{m}$ were stored at $-20^{\circ} \mathrm{C}$ until processed for staining.

Triple fluorescence immunohistochemistry for activated PV neurons (Fos) and perineuronal nets. To examine the activation of PV neurons ensheathed by PNNs, we performed triple immunohistochemistry on brain sections from PND28-PND29 NB or LB pups $60 \mathrm{~min}$ after the onset of fear conditioning experiments. Fos is a commonly used marker for recent neuronal activity (Bullitt, 1990). On day 1 , free-floating sections were brought to room temperature for $30 \mathrm{~min}$, then washed 3 $\times 5 \mathrm{~min}$ in $1 \times$ PBS. They were incubated for $20 \mathrm{~min}$ in $0.3 \% \mathrm{H}_{2} \mathrm{O}_{2}(30 \%$, H1009, Sigma Millipore) in $1 \times$ PBS, then washed $3 \times 5$ min in $1 \times$ PBS. After a $1 \mathrm{~h}$ incubation in blocking solution $(0.02 \%$ Normal Horse Serum, S-2000, Vector Laboratories, $0.004 \%$ Triton X-100, Sigma Millipore, $1 \times \mathrm{PBS}$ ), sections were incubated with the primary anti-PV antibody (1:500, Polyclonal Guinea Pig antiserum, \#195004, Synaptic Systems) for $45 \mathrm{~min}$ at room temperature followed by overnight incubation at $4^{\circ} \mathrm{C}$ on a rotating platform. The next day, sections were washed $3 \times 5 \mathrm{~min}$ in $1 \times \mathrm{PBS}$ and incubated for $2 \mathrm{~h}$ at room temperature in the dark with the Secondary Goat Anti-Guinea Pig antibody Alexa-568 (1:500, A-11075, Invitrogen by Thermo Fisher Scientific). Next, sections were washed $3 \times 5 \mathrm{~min}$ in $1 \times$ PBS and incubated with the primary antiFos antibody (1:500, Rabbit anti-Rat, \#Sc-52, Santa Cruz Biotechnology) as well as the lectin Wisteria floribunda agglutinin (WFA) conjugated with Fluorescein (1:500, FL-1355, Vector Laboratories) for $45 \mathrm{~min}$ at room temperature, then overnight at $4^{\circ} \mathrm{C}$. WFA binds to $\mathrm{N}$-acetylgalactosamine residues and is widely used to detect PNNs (Seeger et al., 1996). On the third day, sections were washed $3 \times 5 \mathrm{~min}$ in $1 \times \mathrm{PBS}$, then incubated for $2 \mathrm{~h}$ with Secondary Donkey Anti-Rabbit antibody Alexa-647 (1:500 dilution in blocking solution, \#711-605-152, Jackson ImmunoResearch Laboratories). Sections were washed $3 \times 5 \mathrm{~min} 1 \times$ PBS and mounted onto charged glass slides using DAPI Hardset mounting medium (H-1500, Vector Laboratories).

Triple fluorescence immunohistochemistry for PV, GAD67 neurons, and perineuronal nets. Using triple immunohistochemistry on adjacent brain sections from PND28-PND29 pups, we examined the following: (1) the total inhibitory cell population $\left(\mathrm{GAD}^{+} 7^{+}\right.$and $\left.\mathrm{PV}^{+}\right)$; (2) the density and percentage of PNN on the total inhibitory cell population; and (3) the density and percentage of $\mathrm{PNN}$ on $\mathrm{GAD}^{+} / \mathrm{PV}^{-}$cells. The protocol was identical to the one described above, except that the primary anti-Fos antibody was replaced with a primary anti-GAD67 antibody (1:500, Mouse Monoclonal, MAB5406, Sigma Millipore).

Microscopy imaging. Pictures of triple immunostained sections were taken with an Olympus BX63 fluorescence microscope and the Olympus F1200 confocal microscope in that order to avoid bleaching. Eight pictures were taken per brain on the BX63: four of the left and four of the right amygdala spanning bregma levels -1.92 to $-3.00 \mu \mathrm{m}$ based on the Paxinos and Watson atlas of the rat brain (Paxinos and Watson, 2005). The pictures on the BX63 were taken at $20 \times$ magnification, with exposure times of $13 \mathrm{~ms}$ for DAPI, $20 \mathrm{~ms}$ for GFP (PNN), $50 \mathrm{~ms}$ for RFP (PV), and $70 \mathrm{~ms}$ for FR (Fos and GAD67). Three $z$-stack images (20 slices at $9 \mathrm{~mm}$ depth) per brain side between bregmas -2.04 and $-2.52 \mu \mathrm{m}$ were captured on the confocal microscope for WFA intensity measurements at $20 \times$ magnification with $0.1 \% 488 \mathrm{~nm}$ laser intensity.

Cell quantification and PNN intensity measurements. Counting of immunostained cells and cells expressing PNNs was manually performed using the QuPath software. The BLA was outlined on four sections per brain side with micrometers $(\mu \mathrm{m})$ as unit of length. Pixel width, pixel height, and voxel depth all equaled 0.5119 . Total counts were converted to cell density measurements expressed as $\mathrm{mm}^{2}$. The 
Table 1. Mother and pup body weights

\begin{tabular}{lllllll}
\hline & Bedding & PND1 & PND4 & PND10 & PND22 & PND28 \\
\hline Mother body weight $(\mathrm{g})$ & NB & $331.5 \pm 8.8$ & $361.9 \pm 7.3$ & $388.9 \pm 5.9$ & $380.6 \pm 5.4$ & - \\
& LB & $328.2 \pm 8.7$ & $350.7 \pm 8.6$ & $388.3 \pm 8.8$ & $362.5 \pm 12.1$ & - \\
Pup body weight $(\mathrm{g})$ & NB & $7.86 \pm 0.19$ & $14.54 \pm 0.39$ & $32.29 \pm 0.91$ & $81.17 \pm 1.06$ & Males: $122.65 \pm 2.34$ \\
& & & & & Females: $119.8 \pm 2.09$ \\
& LB & $7.69 \pm 0.15$ & $12.78 \pm 0.5$ & $27.91 \pm 0.89^{*}$ & $77.11 \pm 1.01^{*}$ & Males: $118.8 \pm 1.98$ \\
& & & & & Females: $116.1 \pm 1.62$
\end{tabular}

Mothers and litters were weighed on PND1, PND4, PND10, and PND22, and pup weight was calculated from the litter weight regardless of sex. Animals were individually weighed on PND28. LB transiently decreased pup body weight on PND10 and PND22 relative to NB animals. Two-way ANOVAs with bedding as a between-subject factor and age as a within-subject factor were performed for mothers and neonates until weaning (PND22), followed by simple effects tests to decompose significant interactions. For PND28, two-way ANOVA was performed with bedding and sex as between-subject factors. Data are mean \pm SEM of $n=14$ or 15 litters/group (PND1, PND4, PND10, PND22) and 12-14 animals/group and sex (PND28).

${ }^{*} p<0.001$.

categories counted in two distinct immunohistochemical series of the same experimental groups were as follows: Series $1: \mathrm{PV}^{+}, \mathrm{PNN}^{+}, \mathrm{PV}^{+}$/ $\mathrm{PNN}^{+}, \mathrm{Fos}^{+}, \mathrm{PV}^{+} / \mathrm{Fos}^{+}, \mathrm{PV}^{+} / \mathrm{Fos}^{+} / \mathrm{PNN}^{+}$; Series $2: \mathrm{PV}^{+}, \mathrm{PNN}^{+}$, $\mathrm{PV}^{+} / \mathrm{PNN}^{+}, \mathrm{GAD}^{+} 7^{+}, \mathrm{GAD}^{+} 7^{+} / \mathrm{PV}^{-}, \mathrm{GAD}^{+} 7^{+} / \mathrm{PV}^{+},{\mathrm{GAD} 67^{+} / \mathrm{PV}^{-} /}^{+}$ $\mathrm{PNN}^{+}, \mathrm{GAD}^{+} / \mathrm{PV}^{+} / \mathrm{PNN}^{+}$. To examine the relative maturity of PNN, WFA fluorescence intensity was measured on three sections per brain side using z stacks as previously described by Slaker et al. (2016), with ImageJ software (National Institutes of Health). All immunohistochemical analyses were performed by experimenters blind to the treatment conditions.

Experimental design and statistical analysis. Body weight data from PND1, PND4, PND10, and PND22 animals ( $n=14$ or 15 animals/group from 14 or 15 litters/group) were analyzed using two-factor ANOVA with bedding as a between-subject factor and day as a within-subject factor. Body weight data for PND28 animals ( $n=12-14$ animals/group and sex from 3-6 litters) were analyzed using two-factor ANOVA with bedding and sex as between-subject factors. All electrophysiological field recordings were obtained from NB and LB animals aged PND22PND28. LTP recordings ( $n=9-11$ slices/group, 1-3 slices/animal, 5-8 animals/group from 2 or 3 litters/group) were analyzed using separate two-factor ANOVAs with sex and bedding or side as between-subject factors, as well as three-factor ANOVA with bedding, sex, and side as between-subject factors. Paired, two-tailed $t$ tests and two-factor ANOVAs with sex and bedding as between-subject factors were used to analyze fiber volley size from LTP recordings in the right BLA $(n=9-11$ slices/group, 1-3 slices/animal, 5-8 animals/group from 2 or 3 litters/ group). Input-output recordings $(n=9-12$ slices/group, $1-3$ slices/animal, 5-8 animals/group from same 2 or 3 litters/group as LTP recordings) were analyzed using two-factor ANOVA with bedding and fiber volley amplitude as between- and within-subject factors, respectively. To further evaluate sex and side differences, three-factor ANOVAs were computed for input-output data with sex or side as between-subject factors and fiber volley amplitude as a within-subject factor. All whole-cell electrophysiological recordings were obtained from NB and LB animals aged PND25-PND28. We confirmed that age interval had no significant effect on the variables measured. Action potential properties ( $n=8$ or 9 neurons/group, 5 or 6 animals/group from 3 or 4 litters/group) were analyzed using two-factor ANOVA with bedding and sex as between-subject factors. NMDAR and AMPAR subunit expression was measured in PND28-PND29 animals ( $n=5$ or 6 animals/group from 3 litters/group) and analyzed using three-factor ANOVA with bedding, sex, and side as between-subject factors. Further, two-factor ANOVA was performed on each BLA side to decompose the sex and bedding effects for NMDAR and AMPAR subunits.

Fear conditioning was performed in PND28-PND29 animals $(n=5$ animals/condition and sex from 2 litters/group) and analyzed using three-factor ANOVA with bedding and treatment or sex as betweensubject factors and tone as a within-subject factor. For the determinations of total cell numbers $\left(\mathrm{PV}^{+}, \mathrm{GAD}^{+} 7^{+}\right.$, and $\left.\mathrm{PNN}^{+}\right)$, both control and fear groups were pooled ( $n=10$ animals/group and sex) from the fear conditioning experiment and analyzed using two-factor ANOVA with bedding and sex as between-subject factors. $\mathrm{PV}^{+}$and $\mathrm{PNN}^{+}$cell densities (see Fig. $7 A-C$ ) were measured from immunohistochemistry Series 1 and 2 sections ( $n=8$ sections/amygdala side), whereas GAD67 ${ }^{+}$ cell densities (see Fig. 7D-F) were determined from immunohistochemistry Series 2 sections ( $n=4$ sections/amygdala side). PNN staining intensity data were obtained from immunohistochemistry Series 1 sections ( $n=3$ sections/amygdala side from 10 animals/group) and analyzed using two-factor ANOVA with bedding and side as between-subject factors. The density of Fos-expressing cells was obtained from immunohistochemistry Series 1 sections $(n=4$ sections/amygdala side) after fear or control testing ( $n=5$ animals/group) and analyzed using three-factor ANOVA with bedding, treatment, and sex as betweensubject factors. Simple effects tests were used to analyze any significant interactions for all data. Data are presented as mean \pm SEM. Statistical significance was set at $p<0.05$. Electrophysiology trace drawings were created with Clampfit (Molecular Devices). Graphs were created with Prism 7 (GraphPad Software).

\section{Results}

\section{LB-reared preweaning animals display a transient reduction} in body weight

Mothers and litters were weighed on PND1, PND4, PND10, and PND22. Pup weight was calculated from the litter weight regardless of sex. After weaning, individual animals were weighed on PND28. Consistent with our previous findings and others (Walker et al., 2017; Guadagno et al., 2018a), LB reduced pup body weight on PND10 $\left(F_{(1,107)}=17.83, p=0.0005\right)$ and PND22 $\left(F_{(1,107)}=15.3, p=0.00016 ; n=14\right.$ or 15 litters/group) (Table 1$)$. There was no significant effect of bedding on body weight of mothers $\left(F_{(1,27)}=0.79=0.38, n=14\right.$ or 15$)$. On PND28, there was no significant effect of bedding $\left(F_{(1,50)}=3.47, p=0.068\right)$, sex $\left(F_{(1,50)}=1.9, p=0.17\right)$, and no bedding $\times$ sex interaction on pup body weight $\left(F_{(1,50)}=0.00074, p=0.97, n=12-14\right.$ animals/group and sex).

\section{LB exposure enhances LTP formation and evoked fEPSP responses in the right BLA of juvenile males exclusively} We previously reported that LB exposure induces synaptic remodeling in the preweaning BLA, with male, but not female, excitatory neurons displaying enhanced spine densities and dendritic lengths (Guadagno et al., 2018a). Increased spine density suggests that those neurons receive stronger excitatory inputs, as evidenced by the heightened input-output relationship we observed in the BLA of PND18-PND22 male pups (Guadagno et al., 2018a). Here, we extended these initial in vitro electrophysiological studies and measured the effects of LB on synaptic plasticity in the left and right BLA using in vitro brain slices $(n=9-12 /$ group, side, and sex) from PND22-PND28 male and female rats ( $n=5-8$ animals/group). The stimulating electrode for all field recordings was placed in the LA, adjacent to the recording electrode in the BLA. Significant induction of fEPSPs with preceding fiber volleys was observed, likely representing depolarization of presynaptic fibers. Fiber volleys, but not fEPSPs, were insensitive 
to DNQX (Fig. $1 E$ ). We induced LTP of fEPSPs in the BLA by HFS (two $1 \mathrm{~s}$ trains of 100 pulses delivered at $100 \mathrm{~Hz}$, separated by $20 \mathrm{~s}$ ) in the LA. Successful LTP in the BLA with similar placement of electrodes has been documented as early as PND25 (Aroniadou-Anderjaska et al., 2001). fEPSP responses 25-30 min after HFS (post-tetanic LTP period) were calculated relative to the last $2 \mathrm{~min}$ of baseline recording (time $13-15 \mathrm{~min}$, pretetanic LTP period) (for slope graphs and representative traces, see Fig. $1 A-D)$. In the left BLA, there was no significant main effect of bedding $\left(F_{(1,35)}=0.89, p=0.76\right)$ or sex $\left(F_{(1,35)}=1.23, p=0.27\right)$, and no bedding $\times$ sex interaction $\left(F_{(1,35)}=1.97, p=0.16\right)$ for LTP as a function of percent of baseline (Fig. $1 F)$. In contrast, in the right $\mathrm{BLA}, \mathrm{LB}$ exposure in males significantly enhanced LTP compared with $\mathrm{NB}$ animals $\left(F_{(1,38)}=18.18, p=0.00013\right)$, whereas this effect was not observed in females $\left(F_{(1,38)}=0.11, p=0.74\right)$ (Fig. $1 F$ ). Additionally, sex differences emerged in the LB group, with males displaying greater LTP formation than females $\left(F_{(1,38)}=7.67, p=0.0086\right)$ (Fig. $\left.1 G\right)$. Two-way ANOVA with sex and side as between-subjects factors revealed a significant effect of side for both $\mathrm{NB}\left(F_{(1,37)}=4.10, p=0.05\right)$ and $\mathrm{LB}$ animals $\left(F_{(1,36)}=30.05, p=0.0001\right)$, with LTP responses being enhanced in the right versus the left BLA. No significant interactions were observed (NB: $F_{(1,37)}=1.67, p=0.2$; LB: $\left.F_{(1,36)}=3.74, p=0.061\right)$. To further analyze side effect, a three-way ANOVA was performed and gave a significant bedding $\times$ sex $\times$ side interaction $\left(F_{(1,73)}=5.43, p=0.022\right)$. LTP in the right BLA ( $569 \%$ of baseline) was significantly increased compared with the left side (183\% of baseline) in LB males: $\left.F_{(1,73)}=34.18, p=0.00001\right)$, as well as in $\mathrm{NB}\left(F_{(1,73)}=4.10, p=0.046\right)$ and $\operatorname{LB}\left(F_{(1,73)}=7.83, p=0.0065\right)$ females, but not in NB males $\left(F_{(1,73)}=0.21, p=0.64\right)$.

To determine whether presynaptic mechanisms could be involved in the increase in LTP after LB exposure, we analyzed fiber volley size from LTP recordings in the right BLA of male and female juveniles. Paired, two-tailed $t$ tests for fiber volley size (comparing percent of baseline vs $100 \%$ ) revealed significant increases in fiber volley size $30 \mathrm{~min}$ after tetanus in the right BLA for males (NB: $t_{(9)}=2.54, p=0.032$; LB: $\left.t_{(10)}=4.55, p=0.001\right)$ and LB females $\left(t_{(10)}=6.92, p=0.00004\right)$, but not NB females $\left(t_{(9)}=2.071, p=0.068\right)$. Two-factor ANOVA yielded no significant effects of bedding $\left(F_{(1,38)}=1.56, p=0.21\right)$ or $\operatorname{sex}\left(F_{(1,38)}=\right.$ $1.37, p=0.24)$ and no bedding $\times$ sex interaction $\left(F_{(1,38)}=0.15\right.$, $p=0.69$ ) for fiber volley size in the right BLA.

We previously showed that fMRI connectivity changes in LB offspring were predominant in the right hemisphere (Guadagno et al., 2018b) and that LB enhances evoked synaptic responses in the BLA of males on PND18-PND22 (Guadagno et al., 2018a), although we did not differentiate left from right BLA slices, nor did we perform electrophysiological recordings in female pups. To probe for potential hemispheric and sex-dependent effects on input-output BLA functioning, in the current study, we evoked fEPSPs at fiber volley sizes ranging from 0.1 to $0.4 \mathrm{mV}$ by adjusting the stimulus intensity accordingly. Two-way ANOVAs were computed with bedding and fiber volley amplitude as betweenand within-subject factors, respectively. As shown in Figure 2, LB-reared males displayed increased fEPSP responses at fiber volley size 0.4 , compared with NB-reared males, in the right BLA only $\left(F_{(1,67)}=11.15, p=0.001\right.$; left BLA bedding effect: $F_{(1,19)}=$ $0.34, p=0.56)$. In females, there was no effect of bedding (left: $F_{(1,17)}=1.46, p=0.24$; right: $\left.F_{(1,17)}=0.013, p=0.91\right)$ or bedding $\times$ fiber volley amplitude interaction in either BLA side (left: $F_{(3,51)}=0.75, p=0.52$; right: $\left.F_{(3,51)}=1.04, p=0.38\right)$. To further evaluate sex and side differences in the BLA, three-factor ANOVAs were computed. In males, the right BLA produced larger fEPSP responses at fiber volley sizes $0.3\left(F_{(1,101)}=5.81\right.$, $p=0.017)$ and $0.4\left(F_{(1,101)}=14.59, p=0.00023\right)$, compared with the left BLA. This lateralized effect was not seen in females (main effect of side: $F_{(1,34)}=2.09, p=0.15$ ). Early chronic stress potentiated lateralization of BLA fEPSP responses, as there was only an effect of side at fiber volley sizes $0.3\left(F_{(1,108)}=6.25, p=0.013\right)$ and $0.4\left(F_{(1,108)}=14.83, p=0.0002\right)$ in LB animals (side $\times$ fiber volley amplitude interaction: $\left.F_{(3,111)}=6.46, p=0.00045\right)$, and no main effect of side in NB animals $\left(F_{(1,34)}=2.87, p=0.099\right)$.

\section{Sex-dependent effects of LB on action potential properties in right BLA neurons of juvenile animals}

Changes in synaptic plasticity could be linked to alterations in intrinsic neuron excitability (Xu et al., 2005). We previously reported that $\mathrm{MEPSC}$ properties remain unchanged under basal conditions in $\mathrm{LB}$ versus $\mathrm{NB}$ preweaning male animals (Guadagno et al., 2018a). Here, we examined the effect of LB on BLA neuron activity under stimulated conditions (Fig. 3). Adolescent social isolation, a form of ELS, has been associated with increased BLA pyramidal neuron excitability in adult male animals (Rau et al., 2015). We proposed that similar changes would occur in BLA neurons of juvenile males following LB exposure. Whole-cell patch-clamp recordings were restricted to the right BLA because the effects of ELS on synaptic plasticity were only observed on that side. We characterized properties of action potential firing in the BLA $(n=8$ or 9 cells/group) in both sexes. Representative traces and corresponding phase plane plots for the first action potential evoked by current step injection are illustrated in Figure $3 A-$ $C$. LB females displayed slower maximal depolarization rates compared with NB females $\left(F_{(1,30)}=5.75, p=0.022\right)$ (Fig. $\left.3 D\right)$, but a trend for the opposite effect was seen in males $\left(F_{(1,30)}=\right.$ $3.22, p=0.082)$. NB males displayed slower maximal depolarization rates compared with $\mathrm{NB}$ females $\left(F_{(1,30)}=7.31, p=\right.$ $0.011)$. There was no effect of bedding $\left(F_{(1,30)}=0.028, p=0.86\right)$, $\operatorname{sex}\left(F_{(1,30)}=0.042, p=0.83\right)$, and no bedding $\times$ sex interaction $\left(F_{(1,30)}=0.047, p=0.82\right)$ for action potential threshold (Fig. 3E). LB animals displayed significant hyperpolarization of resting membrane potentials compared with NB animals $\left(F_{(1,30)}=4.34\right.$, $p=0.045$ ) (Fig. $3 F$ ). The average action potential amplitude of BLA neurons was decreased in LB versus NB females $\left(F_{(1,30)}=\right.$ $5.9, p=0.021)$, and a trend toward the opposite effect was seen in males $\left(F_{(1,30)}=3.15, p=0.085\right)$. NB males had lower action potential amplitude compared with NB females $\left(F_{(1,30)}=8.95\right.$, $p=0.0055$ ) (Fig. $3 G)$. Finally, the total number of action potentials fired did not differ between bedding groups $\left(F_{(1,30)}=1.62\right.$, $p=0.21)$, sexes $\left(F_{(1,30)}=1.98, p=0.16\right)$, and yielded no bedding $\times$ sex interaction $\left(F_{(1,30)}=0.097, p=0.75\right)($ Fig. $3 H)$.

\section{LB-induced changes in NMDAR and AMPAR subunits}

Variations in maternal care have been found to influence NMDAR expression (Bagot et al., 2012) and subunit composition (Bath et al., 2016) in the hippocampus, but nothing is known about the amygdala. Here we evaluated the hemispheric effect of LB on protein expression of the GluN1, GluN2A, and GluN2B subunits (Fig. 4) or GluA1 and GluA2 subunits (Fig. 5) using Western blot. For GluN1 expression, three-way ANOVA revealed no effect of $\mathrm{LB}$ or side in the male amygdala, although LB significantly reduced GluN1 expression, specifically in the right BLA in females $\left(F_{(1,40)}=9.31, p=0.004\right)$. On the same amygdala side, LB females also had significantly lower levels of GluN1 compared with LB males $\left(F_{(1,40)}=7.54, p=0.009\right)$. GluN1 expression was lateralized only in LB females, with decreased 
Left BLA
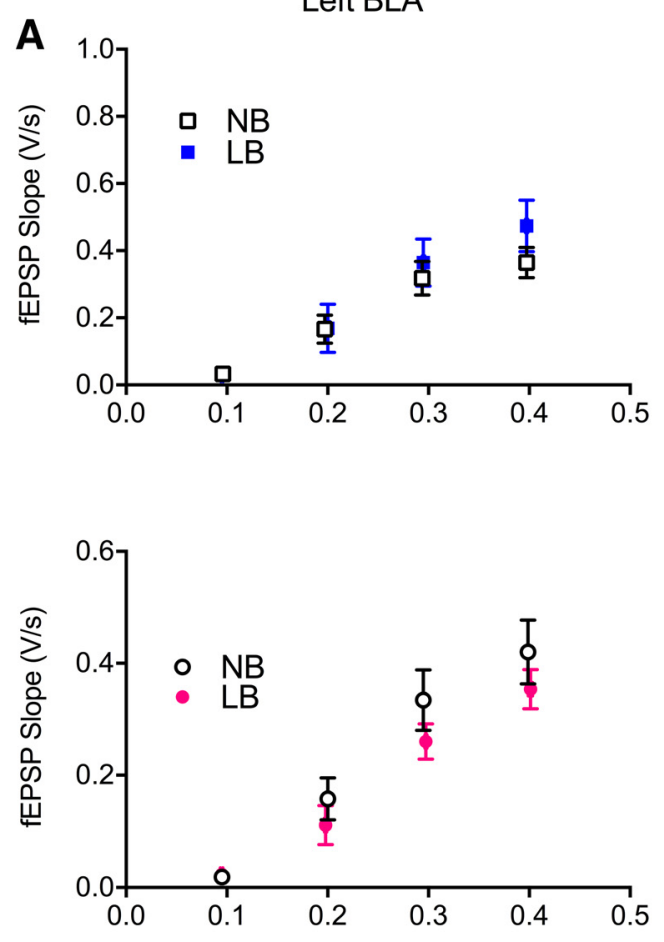

Fiber Volley Amplitude (mV)

B

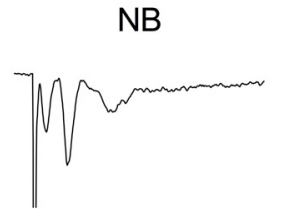

Males

Females
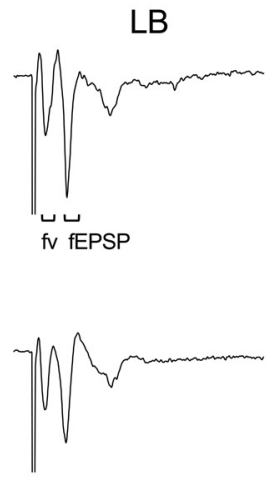

Right BLA
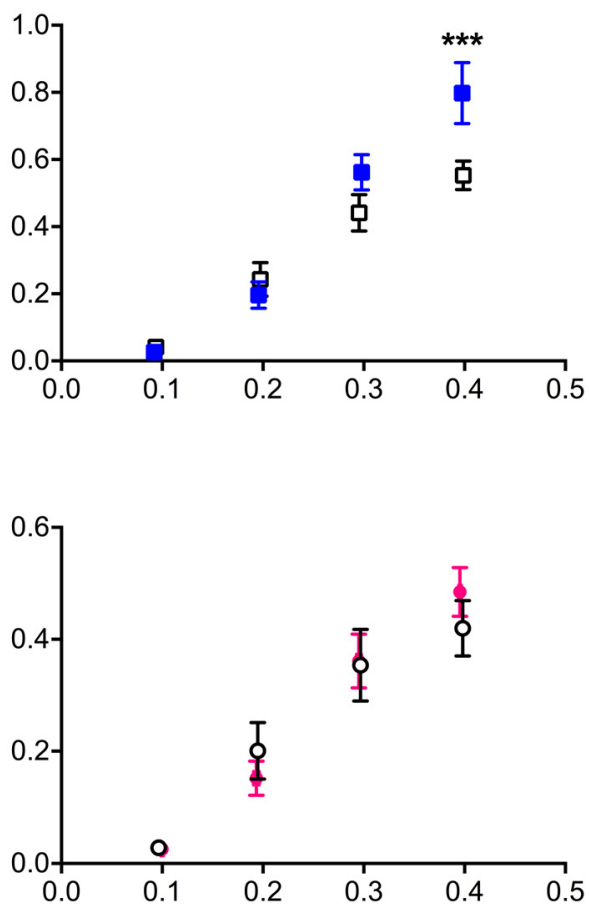

Fiber Volley Amplitude (mV)

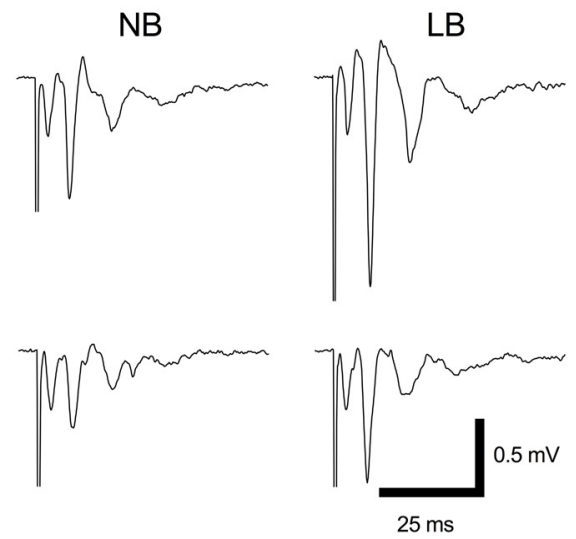

Figure 2. Input-output evoked synaptic responses in the left and right basolateral amygdala of PND22-PND28 animals. $A$, LB exposure significantly increased evoked fEPSP slope in the right, but not the left, BLA of males at fiber volley size 0.4 . B, Representative traces of fEPSP at fiber volley (fv) size 0.4 . Two-way ANOVAs were performed with bedding and fiber volley amplitude as between- and within-subject factors, respectively, and followed by simple effects tests to decompose significant interactions. Data are mean \pm SEM of $n=9-12$ slices/group, 5-8 animals/ group. ${ }^{* * *} p=0.001$.

expression in the right compared with the left BLA $\left(F_{(1,40)}=8.95\right.$, $p=0.0047)$. Further two-way ANOVAs were conducted for each BLA side with bedding and sex as between-subject factors. In the right BLA, there was a significant effect of bedding $\left(F_{(1,20)}=4.62\right.$, $p=0.04)$ and a bedding $\times$ sex interaction $\left(F_{(1,20)}=4.19, p=0.05\right)$, but no effect of sex $\left(F_{(1,20)}=2.99, p=0.09\right)$. As displayed in Figure $4 A$, simple effects tests revealed that LB females had significantly reduced GluN1 expression compared with NB females $\left(F_{(1,20)}=8.8, p=0.007\right)$ and LB males $\left(F_{(1,20)}=7.13, p=0.014\right)$. There were no significant effects of bedding $\left(F_{(1,20)}=0.95\right.$, $p=0.34)$ or sex $\left(F_{(1,20)}=1.07, p=0.31\right)$ and no bedding $\times$ sex interaction $\left(F_{(1,20)}=0.85, p=0.36\right)$ for GluN1 expression in the left BLA. For both GluN2A and GluN2B expression, three-way ANOVA gave no main effects of bedding (GluN2A: $F_{(1,39)}=0.67$, $p=0.41$; GluN2B: $\left.F_{(1,40)}=0.19, p=0.66\right)$, sex $\left(\right.$ GluN2A: $F_{(1,39)}=$
0.44, $p=0.5$; GluN2B: $F_{(1,40)}=2.63, p=0.11$ ), side (GluN2A: $F_{(1,39)}=0.74, p=0.39$; GluN2B: $\left.F_{(1,40)}=0.55, p=0.46\right)$, and no significant interactions. Following two-way ANOVA with bedding and sex as between-subject factors, there were no main effects of bedding (left GluN2A: $F_{(1,19)}=0.06, p=0.81$; right GluN2A: $F_{(1,20)}=0.75, p=0.39$; left GluN2B: $F_{(1,20)}=0.08, p=0.78$; right GluN2B: $\left.F_{(1,20)}=0.11, p=0.74\right)$ or sex (left GluN2A: $F_{(1,19)}=$ $0.33, p=0.57$; right GluN2A: $F_{(1,20)}=0.16, p=0.69$; left GluN2B: $F_{(1,20)}=0.83, p=0.37$; right GluN2B: $\left.F_{(1,20)}=1.82, p=0.19\right)$ and no significant interactions for GluN2A (Fig. $4 B$ ) or GluN2B (Fig. 4C) expression in either the left or right BLA.

Similarly to NMDAR, few results have been documented for developmental changes in AMPAR subunits following early life adversity (Opendak et al., 2018). For the GluA1 subunit, a threeway ANOVA with bedding, sex, and side as between-subject 
A

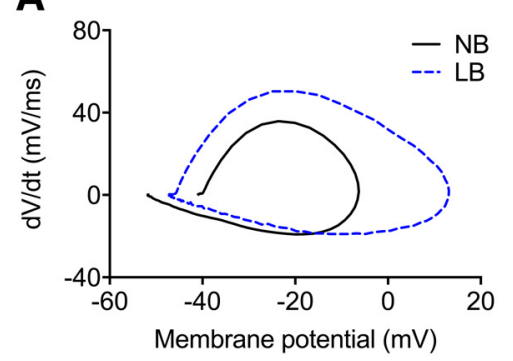

C
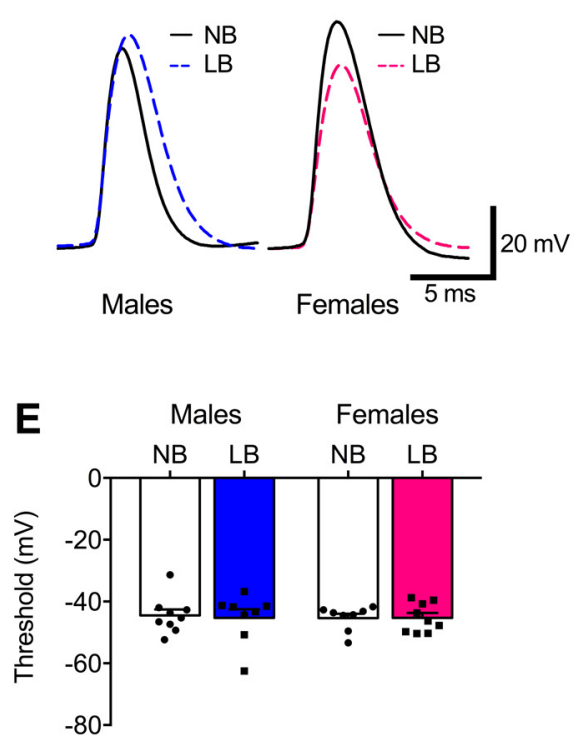

G

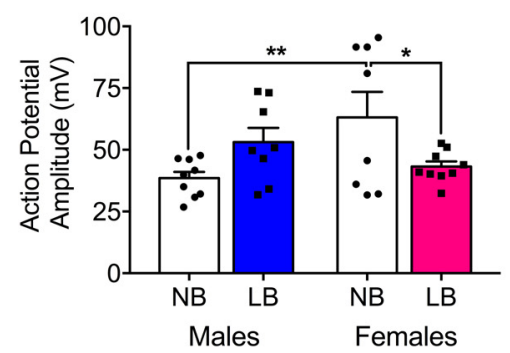

B

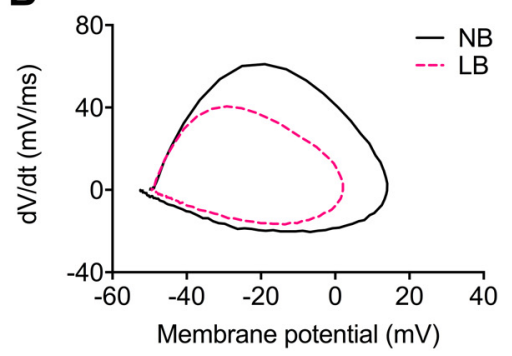

D

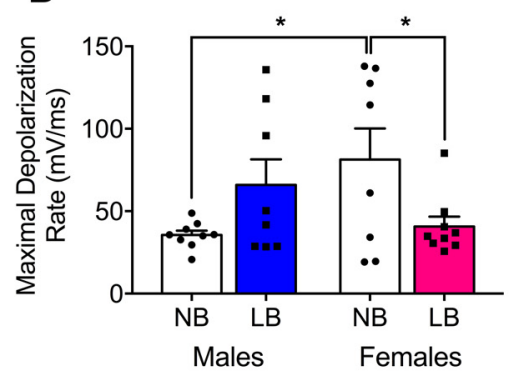

$\mathbf{F}$

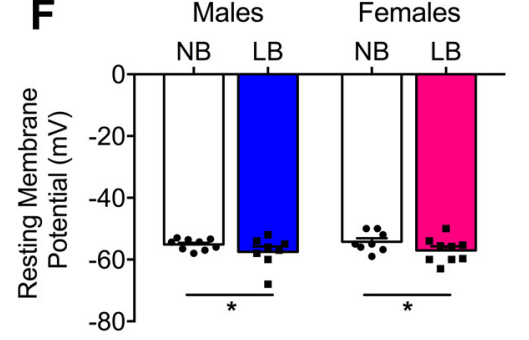

H

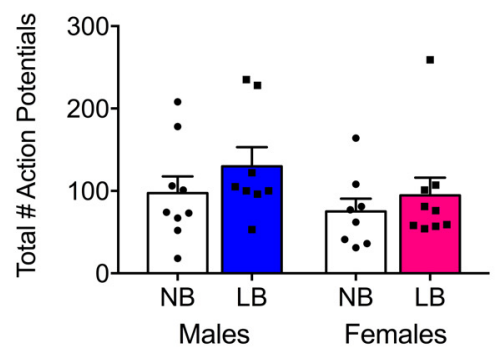

Figure 3. Action potential properties of neurons in the right BLA of PND22-PND28 NB and LB offspring. A-C, Representative traces and corresponding phase plane plots for the first spike elicited by a $10 \mathrm{pA}$ current step injection. $\boldsymbol{D}$, Maximal depolarization rate was decreased in LB versus NB females, and in NB males compared with NB females. $\boldsymbol{E}$, Conversely, action potential threshold was not significantly affected by bedding condition. $\boldsymbol{F}$, Resting membrane potential was hyperpolarized in animals exposed to $L B$ conditions. $\mathbf{G}$, Action potentials fired from BLA neurons were of a lower amplitude in LB compared with NB females, as well as in NB males compared with NB females. $\boldsymbol{H}$, The total number of action potentials fired did not differ between groups. Two-way ANOVAs with bedding and sex as between-subject factors were performed and followed by simple effects tests to decompose significant interactions. Data are mean \pm SEM of $n=8$ or 9 neurons/group, 5 or 6 animals/group. ${ }^{*} p<0.05$. ${ }^{* *} p<0.01$.

factors revealed a significant effect of bedding $\left(F_{(1,40)}=6.20\right.$, $p=0.017)$ and side $\left(F_{(1,40)}=5.59, p=0.023\right)$, but no effect of sex $\left(F_{(1,40)}=1.7, p=0.199\right)$ or significant interactions. As shown in Figure $5 \mathrm{~A}$, when GluA1 data were analyzed per side using a twoway ANOVA with bedding and sex as between-subject factors, there were no significant effects of bedding or sex in either the left (bedding: $F_{(1,20)}=3.19, p=0.089$; sex: $F_{(1,20)}=1.2, p=0.28$ ) or right BLA (bedding: $F_{(1,20)}=3.01, p=0.098$; sex: $F_{(1,20)}=0.55$, $p=0.46$ ). For GluA2 subunit expression, three-way ANOVA revealed a significant effect of sex $\left(F_{(1,40)}=4.67, p=0.037\right)$ and side $\left(F_{(1,40)}=\right.$ $14.51, p=0.00047)$, but no bedding effect $\left(F_{(1,40)}=2.91, p=0.096\right)$ or interactions. Further, two-way ANOVA per side followed by simple effects tests revealed that, in the right BLA only, LB males exhibited a significant reduction in GluA2 expression compared with $\mathrm{NB}$ males $\left(F_{(1,20)}=\right.$ 6.74, $p=0.017)$ and LB females $\left(F_{(1,20)}=\right.$ $7.61, p=0.012)$. No main effects of bedding $\left(F_{(1,20)}=0.043, p=0.83\right)$ or $\operatorname{sex}\left(F_{(1,20)}=\right.$ $0.042, p=0.82$ ) or significant interactions were observed for GluA2 expression in the left BLA.

\section{Behavioral responses to fear} conditioning in juvenile animals

Changes in BLA synaptic plasticity are essential for fear learning in both early development (Thompson et al., 2008) and adulthood (Suvrathan et al., 2014). In particular, in males, ELS exposure can negatively impact these synaptic learning processes to enhance anxiety and fear behaviors in adulthood (Guadagno et al., 2018a). In the current study, we examined whether enhanced synaptic plasticity in LB males would associate with increased fear conditioning in the juvenile period. At this age (PND28-PND29), and in accordance with our findings, rats can be conditioned to express adult-like levels of fear (Jovanovic et al., 2013). As illustrated in Figure 6, fear conditioning was successful to increase freezing in both male and female on PND28-PND29 juvenile animals. A three-way ANOVA gave a significant treatment $x$ tone interaction for both males $\left(F_{(5,80)}=10.56, \quad p=0.00001\right)$ and females $\left(F_{(5,80)}=19.29, \quad p=0.00001\right)$. Males and females that were fear-conditioned displayed more freezing behavior during the $30 \mathrm{~s}$ tone compared with controls at tones 2 (males: $F_{(1,85)}=8.23, p=0.0052$; females: $\left.\quad F_{(1,60)}=13.18, \quad p=0.00056\right)$ through tone 6 (males: $F_{(1,85)}=22.29$, $p=0.00001$; females: $F_{(1,60)}=35.48, p=$ $0.00001)$. There were no sex differences in freezing for fear $\left(F_{(1,16)}=0.16\right.$, $p=0.69)$ or in control animals $\left(F_{(1,16)}=\right.$ $0.17, p=0.68)$. In contrast to what we previously documented in adult male rats (Guadagno et al., 2018a), we did not find a significant effect of bedding on freezing behavior in juvenile (PND28-PND29) male $\left(F_{(1,8)}=0.00, p=0.99\right)$ or female $\left(F_{(1,8)}=1.75, p=0.22\right)$ rats.

\section{Effect of LB, sex, and side on total inhibitory neurons and} PNN-positive cells in the BLA

For the determinations of total cell numbers $\left(\mathrm{PV}^{+}, \mathrm{GAD} 67^{+}\right.$, and $\left.\mathrm{PNN}^{+}\right)$, we pooled both control and fear groups $(n=10$ pups/group and sex) from the fear conditioning experiment that 
Left BLA Right BLA
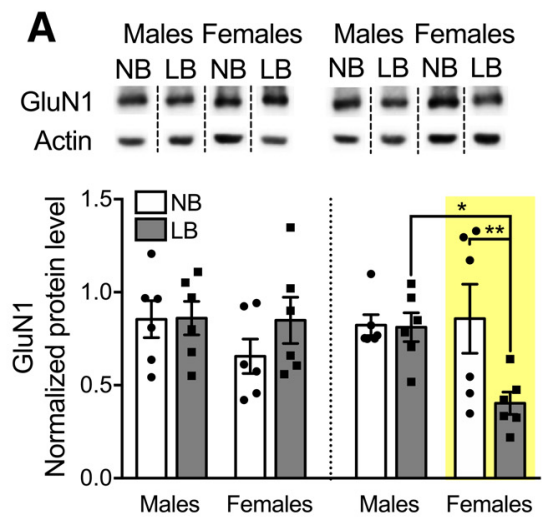

B Males Females Males Females NB LB NB LB NB LB NB LB
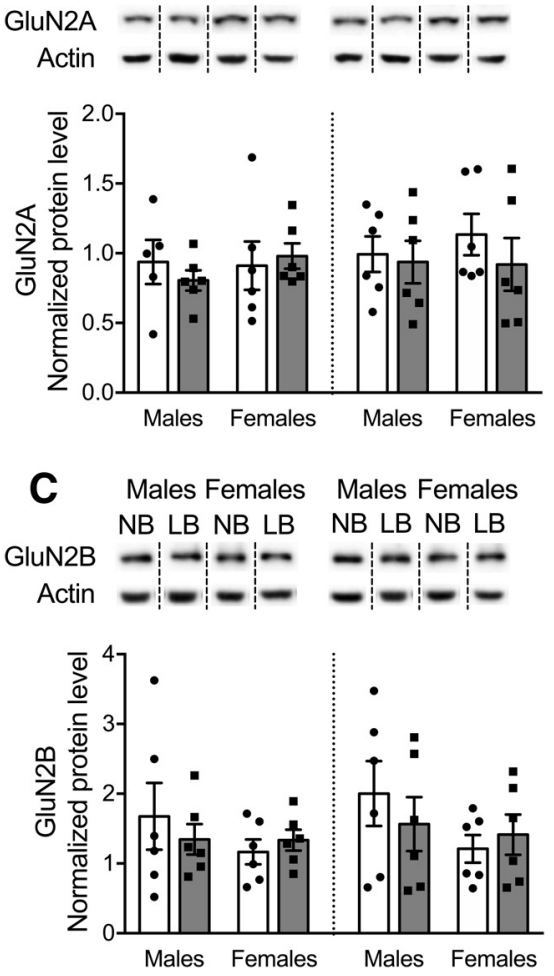

Figure 4. Expression of NMDA receptor subunits GluN1, GluN2A, and GluN2B in the left and right BLA of PND28-PND29 animals. Protein levels were normalized to actin, and representative Western blot bands are displayed above each graph. Dashed lines are used to divide bands from different parts of the same or different gels. Samples originating from male and female offspring were run on different gels. $\boldsymbol{A}$, In the right BLA, GluN1 expression was significantly reduced in $L B$ relative to NB females. LB females also displayed lower levels of GluN1 compared with LB males. B, C, GluN2A as well as GluN2B expression was unaffected by early chronic stress. Two-way ANOVAs with bedding and sex as between-subject factors were performed by side and followed by simple effects tests to decompose significant interactions. Data are mean \pm SEM of $n=5$ or 6 animals/group. ${ }^{*} p<0.05$. ${ }^{* *} p<0.01$.

is displayed in Figure 6. We assumed that the total number of inhibitory cells $\left(\mathrm{PV}^{+}\right.$and $\left.\mathrm{GAD}^{+}\right), \mathrm{PV}^{+}$, or $\mathrm{PNN}^{+}$cells would not be affected by acute exposure to fear conditioning. This was confirmed by the lack of significant differences in a three-way ANOVA with bedding (NB or LB), treatment (control, fear), and sex analysis for both the left (total inhibitory cell population density: $F_{(1,32)}=0.03, p=0.85$; PV density: $F_{(1,32)}=0.01, p=0.92$; PNN density: $F_{(1,32)}=0.01, p=$ 0.92 ) and right amygdala (total inhibitory cell population

\section{Left BLA Right BLA}
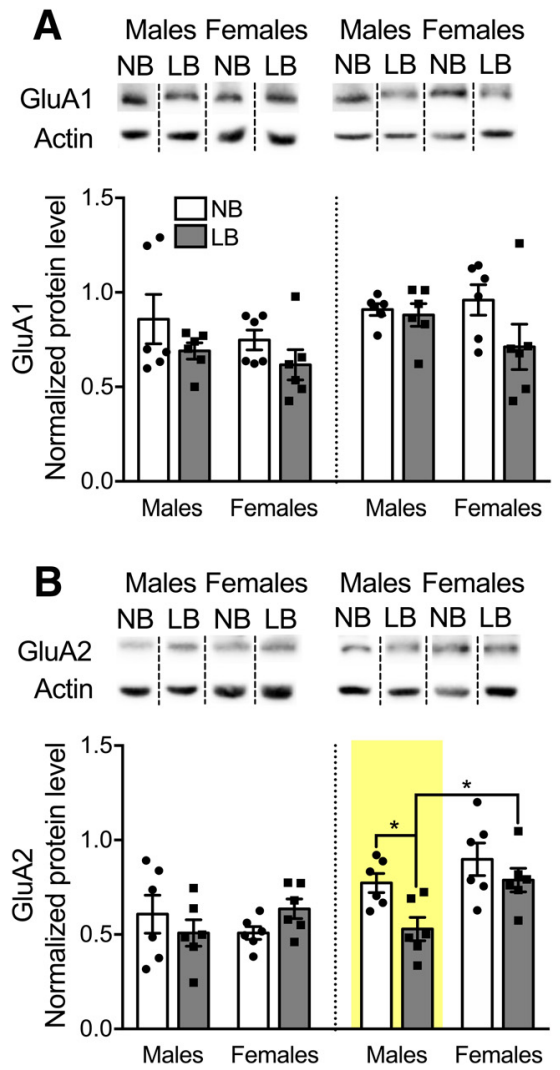

Figure 5. Expression of AMPAR subunits GluA1 and GluA2 in the left and right BLA of PND28-PND29 animals. Protein levels were normalized to actin, and representative Western blot bands are displayed above each graph. Dashed lines are used to divide bands from different parts of the same or different gels. Samples originating from male and female offspring were run on different gels. $\boldsymbol{A}$, GluA1 expression was unaffected by LB conditions. $\boldsymbol{B}$, GluA2 expression was significantly decreased in LB males compared with NB males $(p=0.017)$ and LB females $(p=0.012)$, only in the right BLA. Two-way ANOVAs with bedding and sex as between-subject factors were performed by side and followed by simple effects tests to decompose significant interactions. Data are mean \pm SEM of $n=5$ or 6 animals/group. ${ }^{*} p<0.05$.

density: $F_{(1,32)}=1.85, p=0.18 ;$ PV density: $\left(F_{(1,32)}=0.01\right.$, $p=0.94$; PNN density: $\left.F_{(1,32)}=1.04, p=0.31\right)$.

$\mathrm{PV}^{+}$neurons constitute $\sim 50 \%$ of the total population of inhibitory GABAergic interneurons in the adult BLA (Spampanato et al., 2011); and although they emerge around PND14, they are considered morphologically mature by PND30 (Berdel and Moryś, 2000). In juveniles (PND28) and in accordance with others using a modified ELS procedure (Santiago et al., 2018), the density of $\mathrm{PV}^{+}$cells was not changed by either sex or bedding, in either side of the BLA (Fig. 7A) (left BLA: sex: $F_{(1,36)}=0.02, p=0.88$; bedding: $F_{(1,36)}=1.09, p=0.3$; interaction: $F_{(1,36)}=1.16, p=0.28$; right BLA: sex: $F_{(1,36)}=1.19, p=0.28$; bedding: $F_{(1,36)}=0.19, p=0.66$; interaction: $\left.F_{(1,36)}=0.46, p=0.5\right)$. The density of total inhibitory cells (Fig. 7D) was also not affected by either sex or bedding, in either side of the BLA (left BLA: sex: $F_{(1,36)}=2.53, p=0.12$; bedding: $F_{(1,36)}=0.67, p=0.41$; interaction: $F_{(1,36)}=2.3, p=0.13$; right BLA: sex: $F_{(1,36)}=0.21$, $p=0.65$; bedding: $F_{(1,36)}=0.42, p=0.51$; interaction: $F_{(1,36)}=1.51$, $p=0.22)$. In the left BLA, we found an overall sex effect on PNN density, whereby PNN density was increased in males relative to females $\left(F_{(1,36)}=6.57, p=0.014\right)$, but no bedding effect $\left(F_{(1,36)}=1.51, p=0.22\right)$ or significant sex $\times$ bedding interaction 

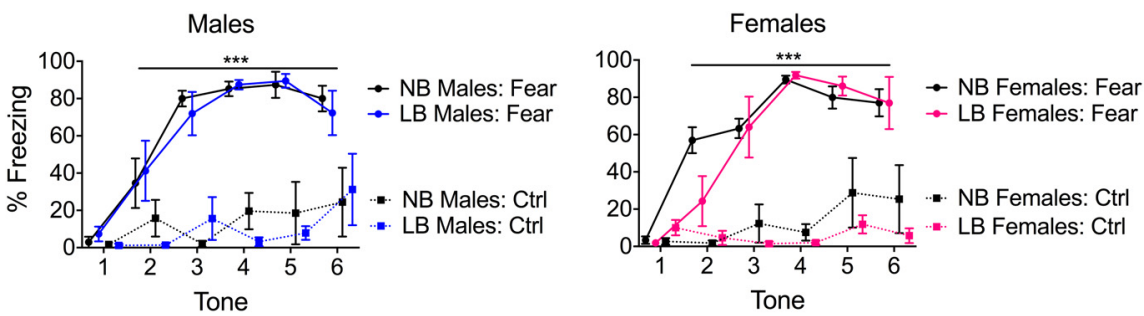

Figure 6. Percentage of freezing time during exposure to a $30 \mathrm{~s}$ tone paired with shock in male and female PND28 PND29 pups from either NB or LB conditions. Control (Ctrl) animals were placed in the same context as fear animals, but not exposed to tone or shock. Although fear conditioning was successful in both males and females, we did not find significant effects of early rearing conditions on freezing in either fear or control group animals. Three-way ANOVAs with bedding and treatment as between-subject factors and tone as a within-subject factor were performed and followed by simple effects tests to decompose significant interactions. Data are mean \pm SEM of $n=5$ animals/group. ${ }^{* * *} p<0.001$, Fear versus Control tones 2-6.

$\left(F_{(1,36)}=3.3, p=0.077\right)$ (Fig. $\left.7 B\right)$. For PNN density in the right $\mathrm{BLA}$, there were significant effects of $\operatorname{sex}\left(F_{(1,36)}=8.79, p=\right.$ $0.0053)$ and bedding $\left(F_{(1,36)}=4.23, p=0.046\right)$, and a sex $\times$ bedding interaction $\left(F_{(1,36)}=7.79, p=0.0083\right)$. In the right BLA only, LB males had significantly more PNN compared with NB males $\left(F_{(1,36)}=11.76, p=0.0015\right)$, whereas no bedding effect was found in females $\left(F_{(1,36)}=0.27, p=0.6\right)$ (Fig. $\left.7 B\right)$. As a result, we discovered a significant effect of sex only in the LB condition, with males having more PNN than females $\left(F_{(1,36)}=16.57, p=0.00025\right)$.

Strikingly, $\mathrm{LB}$ males had more $\mathrm{PV}^{+}$cells surrounded by $\mathrm{PNN}$ compared with NB males in both the left $\left(F_{(1,36)}=5.87, p=0.02\right)$ and right $\mathrm{BLA}\left(F_{(1,36)}=19.76, p=0.00008\right)$ (Fig. $\left.7 C\right)$. LB males also had more $\mathrm{PV}^{+}$cells expressing $\mathrm{PNN}$ compared with $\mathrm{LB}$ females, only in the right BLA $\left(F_{(1,36)}=35.67, p=0.00001\right)$. As illustrated in Figure $7 E$, only in the right BLA did LB males have more PNN on the total inhibitory cell population (GAD67 and PV) compared with $\mathrm{NB}$ males $\left(F_{(1,36)}=10.92, p=0.0021\right)$. LB males also had more PNN associated with the total inhibitory cell population compared with LB females $\left(F_{(1,36)}=14.14\right.$, $p=0.0006)$. To identify whether significant differences for PNN on total inhibitory cells were primarily driven by $\mathrm{PNN}$ on $\mathrm{PV}^{+}$ cells, we determined the density of PNN surrounding GAD67 ${ }^{+}$/ $\mathrm{PV}^{-}$cells (color bars within each bar) and found a significant main effect of bedding in the right $\left(F_{(1,36)}=5.73, p=0.022\right)$, but not the left BLA $\left(F_{(1,36)}=1.41, p=0.24\right)$ (Fig. $\left.7 E\right)$. There were no effects of sex (left: $F_{(1,36)}=1.87, p=0.17$; right: $F_{(1,36)}=0.00$, $p=0.99$ ) or sex $\times$ bedding interaction in either BLA side (left: $F_{(1,36)}=0.14, p=0.71$; right: $\left.F_{(1,36)}=1.72, p=0.19\right)$.

In order to examine how many $\mathrm{PV}^{+}$cells harbor $\mathrm{PNN}$, we calculated the percentages of $\mathrm{PV}^{+}$cells expressing $\mathrm{PNN}$ over the total PV cell population. There was a significant sex $\times$ bedding interaction for percentages of $\mathrm{PV}$ cells with $\mathrm{PNN}$ in the left $\left(F_{(1,36)}=5.27, p=0.027\right)$ and right $\operatorname{BLA}\left(F_{(1,36)}=16.7, p=\right.$ $0.00023)$. In the left BLA, LB increased the percentage of PV cells with PNN in males, but not females (males: NB: $29 \%$, LB: $35 \%$; females: NB: $32 \%$, LB: $30 \%$ ). The same was observed for the right BLA where $\mathrm{LB}$ increased the percentage of $\mathrm{PV}$ cells with PNN in males $\left(F_{(1,36)}=22.55, p=0.00003, \mathrm{NB}: 36 \%, \mathrm{LB}\right.$ : $51 \%)$, but not females $\left(F_{(1,36)}=1.68, p=0.2, \mathrm{NB}: 34 \%, \mathrm{LB}\right.$ : $31 \%)$. LB males also displayed a greater percentage of PV cells with PNN relative to LB females $\left(F_{(1,36)}=41.13\right.$, $p=0.00001)$ in the right BLA.

We estimated which cell type was associated with PNNs in the BLA by calculating the percentage of PNN on total inhibitory cells $\left(\mathrm{GAD} 67^{+} \mathrm{PV}\right)$ over the total PNN cell population (Fig. $7 F$ ). In the left BLA, two-way ANOVA revealed no effect of sex $\left(F_{(1,36)}=1.86, p=0.18\right)$ or bedding $\left.F_{(1,36)}=0.31, p=0.58\right)$ and no sex $\times$ bedding interaction $\left(F_{(1,36)}=1.65\right.$, $p=0.2)$. In the right BLA, there was an effect of $\operatorname{sex}\left(F_{(1,36)}=4.52, p=0.04\right)$, with males displaying greater percentages of PNN on total inhibitory cells relative to females (33 vs 30\%), but no effect of bedding $\left(F_{(1,36)}=2.01, p=0.16\right)$ or sex $\times$ bedding interaction $\left(F_{(1,36)}=2.19, p=0.14\right)$. The percentages of PNN on GAD67 $7^{+} / \mathrm{PV}^{-}$ cells (color bars within treatment bars) ranged between $0.62 \%$ and $1.82 \%$, indicating that the vast majority of PNNs on inhibitory cells were on those neurons that were $\mathrm{PV}^{+}$(Fig. $7 F$ ). In the right BLA, there was a significant effect of bedding $\left(F_{(1,36)}=\right.$ $5.82, p=0.021)$, whereby LB animals had a higher percentage of PNN on $\mathrm{GAD}^{+} 7^{+}$/ $\mathrm{PV}^{-}$cells compared with $\mathrm{NB}$ animals, but no sex effect $\left(F_{(1,36)}=0.0025, p=0.96\right)$ or sex $\times$ bedding interaction $\left(F_{(1,36)}=\right.$ $0.94, p=0.33)$. In the left BLA, there were no effects of sex $\left(F_{(1,36)}=0.15, p=0.69\right)$, bedding $\left(F_{(1,36)}=1.7, p=0.2\right)$, or sex $\times$ bedding interaction $\left(F_{(1,36)}=0.0044, p=0.94\right)$ for percentages of $\mathrm{PNN}$ on $\mathrm{GAD} 67^{+} / \mathrm{PV}^{-}$cells.

In addition to PNN cell density, the maturation stage of these lattice-like structures is important to establish their function in neurotransmission. We next asked whether PNN maturity stage, as determined by the intensity of the WFA staining (Slaker et al., 2016), would be altered by LB in either side of the BLA. There was no significant effect of fear treatment on PNN intensity; therefore, both control and fear groups were pooled (three-way ANOVA: left BLA: $F_{(1,32)}=1.7, p=0.2$; right BLA: $F_{(1,32)}=3.52$, $p=0.069)$. WFA intensity measures showed that there was a significant effect of BLA side as PNN in the right BLA displayed significantly more intense staining compared with the left BLA in males $\left(F_{(1,36)}=5.85, p=0.02\right)$, but not females $\left(F_{(1,36)}=0.25\right.$, $p=0.62$ ) (Fig. 8). This suggests that PNN maturation in males is accelerated in the right amygdala to possibly accommodate lateralized BLA functions. Although PNN maturity was found to be decreased in the BLA of weaning age rats by early life trauma (PND8-PND12) (Santiago et al., 2018), in our study there was no significant effect of bedding in either sex (males: $F_{(1,36)}=0.83$, $p=0.36$; females: $\left.F_{(1,36)}=1.47, p=0.23\right)$.

\section{Lateralized and sex-dependent cellular responses to fear conditioning after LB}

To investigate the effects of LB on cellular activation in the BLA, we measured the density of Fos-expressing cells 60 min after the onset of fear conditioning or control testing. Three-way ANOVA revealed asymmetrical effects of sex and treatment on expression of Fos ${ }^{+}$cells (Fig. 9A,B). Notably, only in the right BLA did males have higher Fos ${ }^{+}$cell density compared with females $\left(F_{(1,32)}=7.08, p=0.012\right)$. Animals in the fear treatment group displayed enhanced $\mathrm{Fos}^{+}$cell density compared with control animals exclusively in the right amygdala as well $\left(F_{(1,32)}=\right.$ 6.27, $p=0.017)$. Fear conditioning significantly enhanced the activation of $\mathrm{PV}^{+}$cells in the left BLA in all animals $\left(F_{(1,32)}=\right.$ 7.63, $p=0.0094$ ) (Fig. 9C). In the right $\mathrm{BLA}, \mathrm{PV}^{+}$cells of $\mathrm{NB}$, but not $\mathrm{LB}$, males were significantly activated in response to fear treatment $\left(F_{(1,32)}=22.34, p=0.00004\right)$ (Fig. 9D). Control LB males already displayed significantly more activated $\mathrm{PV}^{+}$cells compared with $\mathrm{NB}$ males $\left(F_{(1,32)}=8.2, p=0.0073\right)$. In line with these findings, we found blunted $\mathrm{PV}^{+}$cell activation in the $\mathrm{LB}$ compared with NB fear group $\left(F_{(1,32)}=9.6, p=0.004\right)$. In NB 
A

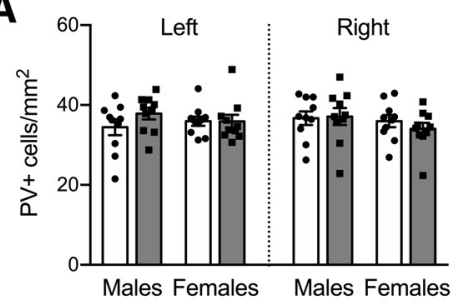

D

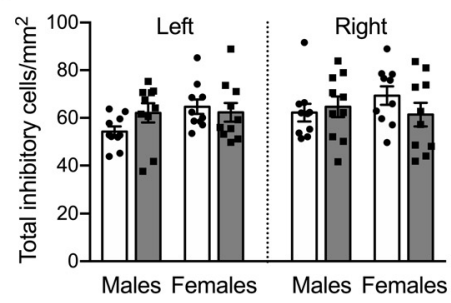

B

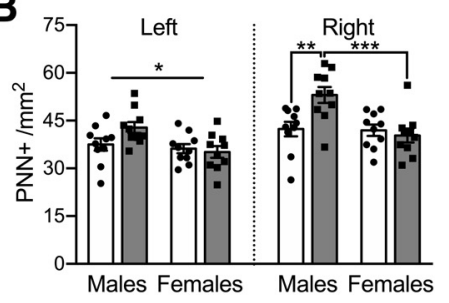

E

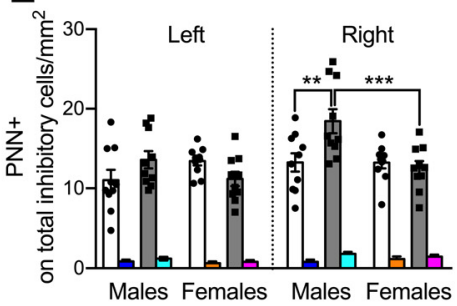

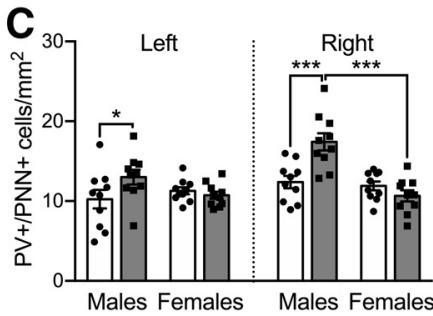

$\mathbf{F}$

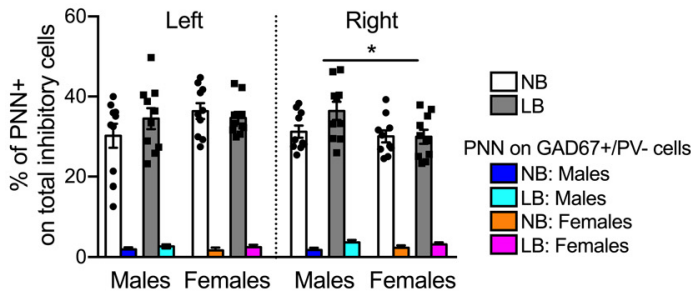

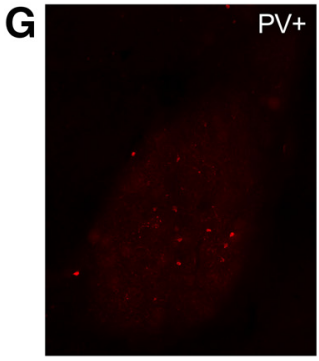
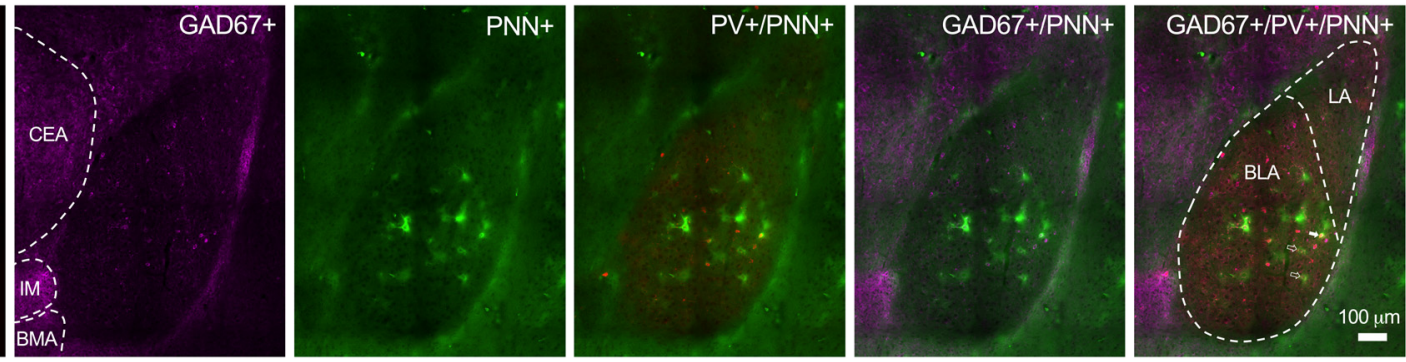

Figure 7. $\mathrm{PV}^{+}$interneuron, total inhibitory $\left(\mathrm{GAD}-67^{+}\right)$cell population, and PNN expression in the left and right BLA of male and female juvenile rats on PND28-PND29. $\boldsymbol{E}, \boldsymbol{F}$, Colored bars (blue, turquoise, orange, magenta) represent PNN on $\mathrm{GAD6}^{+} / \mathrm{PV}^{-}$cells. $\boldsymbol{A}$, Early bedding conditions did not affect PV ${ }^{+}$cell density in the left or right BLA in either sex. $\boldsymbol{B}$, In the left BLA, PNN density was heightened in males compared with females. Simple effects tests showed that LB males had significantly increased PNN density in the right BLA compared with NB males $(p=0.0015)$ and LB females $(p=0.00025)$. $C$, In the left $(p=0.02)$ and right BLA $(p=0.00008)$, LB-exposed male rats expressed more PV ${ }^{+}$cells ensheathed with PNN than NB males. Only in the right BLA did LB males display more $\mathrm{PV}^{+} / \mathrm{PNN}^{+}$cells relative to $\mathrm{LB}$ females $(p=0.00001)$. $\boldsymbol{D}$, The density of total inhibitory cells was not affected by sex or bedding in either side of the BLA. $\boldsymbol{E}$, In the right BLA only, LB males displayed more PNN on the total inhibitory cell population compared with NB males $(p=0.0021)$ and LB females $(p=0.0006)$. The density of PNN surrounding GAD67 ${ }^{+} / \mathrm{PV}^{-}$cells was increased in LB (turquoise and magenta bars) versus NB animals (blue and orange bars) $(p=0.022)$, again only on the right side. $\boldsymbol{F}$, In the right BLA exclusively, males showed greater percentages of PNN on the total inhibitory cell population relative to females. LB animals (turquoise and magenta bars) had a higher percentage of PNN on $\mathrm{GAD} 67^{+} / \mathrm{PV}^{-}$cells compared with NB animals (blue and orange bars) in the right $(p=0.021)$, but not the left, BLA. G, Representative fluorescence microscopy images (20 $\times$ magnification) taken from the right BLA (bregma -2.04) in LB male pups showing PV ${ }^{+}$(red), GAD67 ${ }^{+}$(pink), and PNN ${ }^{+}$(green) cells and the merged expression of $\mathrm{PV}^{+} / \mathrm{PNN}^{+}, \mathrm{GAD67}^{+} / \mathrm{PNN}^{+}, \mathrm{and}$ $\mathrm{GAD}^{+} 7^{+} / \mathrm{PV}^{+} / \mathrm{PNN}^{+}$cells. The BLA and LA are outlined in the GAD67 $/ \mathrm{PV}^{+} / \mathrm{PNN}^{+}$image. Solid arrowhead indicates a GAD67 $/ \mathrm{PV}^{+} / \mathrm{PNN}^{+}$cell. Clear arrowheads indicate PNN ${ }^{+}$cells not surrounding any labeled inhibitory cell. The central amygdala (CeA), intercalated amygdala nucleus (IM), and basomedial amygdala (BMA) are outlined in the GAD67 ${ }^{+}$image. Data are mean \pm SEM of $n=10$ animals/group (8 sections per amygdala side for $\boldsymbol{A}-\boldsymbol{C}$, 4 sections per amygdala side for $\boldsymbol{D}-\boldsymbol{F}$, control and fear group animals combined). Scale bar, $100 \mu \mathrm{m}$. Two-way ANOVAs with bedding and sex as between-subject factors were performed and followed by simple effects tests to decompose significant interactions. ${ }^{*} p<0.05 .{ }^{* *} p<0.01$. ${ }^{* * *} p<0.001$.

animals that were fear treated, activation of $\mathrm{PV}^{+}$ cells was higher in males compared with females $\left(F_{(1,32)}=5.4, p=0.026\right)$. Last, we measured the density of activated $\mathrm{PV}^{+}$also expressing $\mathrm{PNN}$ (Fig. 9E,F). In the left BLA, there was no main effect of bedding $\left(F_{(1,32)}=1.4, p=0.24\right)$, sex $\left(F_{(1,32)}=1.04, p=0.31\right)$, or treatment $\left(F_{(1,32)}=\right.$ $3.18, p=0.084)$ and no significant interactions. Fear conditioning only increased the density of $\mathrm{PNN}$ around activated $\mathrm{PV}^{+}$cells in the right $\operatorname{BLA}\left(F_{(1,32)}=5.15, p=0.03\right)$.

\section{Discussion}

In this study, we examined whether ELS through exposure to suboptimal rearing conditions (LB) would affect BLA synaptic plasticity and neuron excitability in juvenile rats in a sex- and hemispheric-dependent manner. Our novel findings are that LB exposure enhanced BLA LTP exclusively on the right side in males, with no changes on
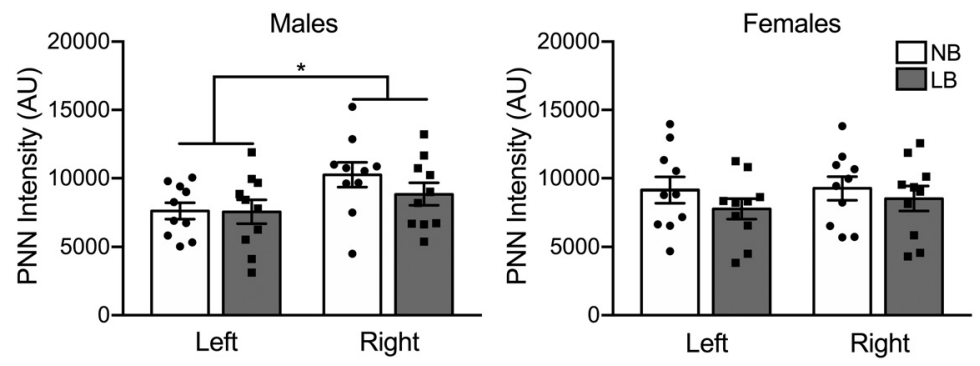

Figure 8. PNN intensity in the left and right basolateral amygdala of male and female PND28-PND29 rats. Intensity is expressed in arbitrary units (AU). The right BLA displayed increased PNN intensity compared with the left BLA in males only. Two-way ANOVAs with bedding and sex as between-subject factors were performed and followed by simple effects tests to decompose significant interactions. Data are mean \pm SEM of $n=10$ animals/group (Control and fear group animals combined). ${ }^{*} p<0.05$.

either side in females. Right BLA neuronal excitability was marginally increased in LB males with reduced GluA2 expression, but fear-induced activity of PV interneurons was reduced in the right, but not the left, BLA. PV interneurons in LB males also 

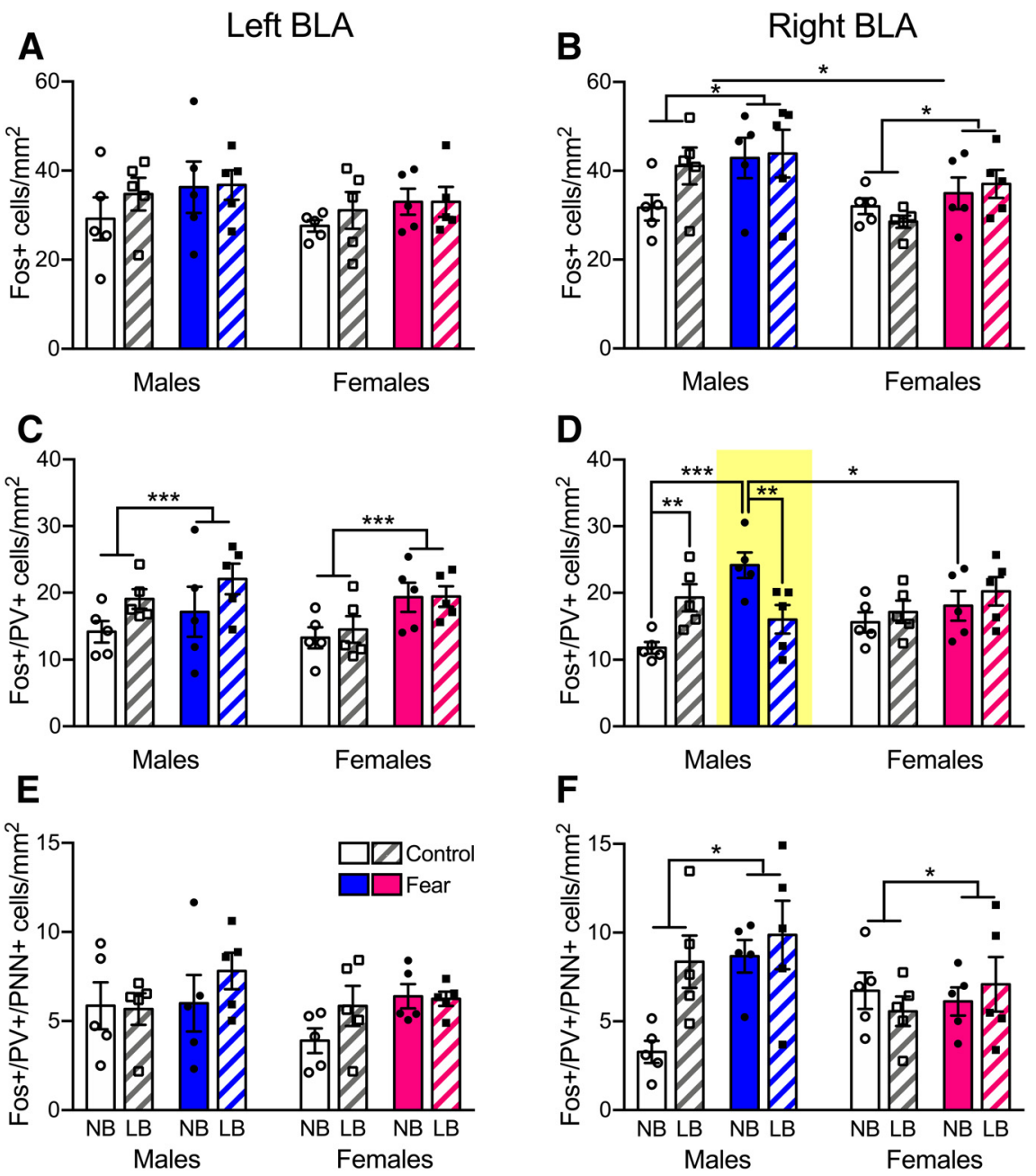

Figure 9. $\mathrm{Fos}^{+}, \mathrm{PV}^{+}$, and $\mathrm{PNN}^{+}$cell density after fear conditioning in PND28-PND29 animals. $\boldsymbol{A}, \boldsymbol{B}, \mathrm{Fos}^{+}$cell density was elevated only in the right BLA of males compared with females and fear-conditioned versus control animals. $\boldsymbol{C}$, Fear treatment increased the density of Fos-activated $\mathrm{PV}^{+}$cells in the left BLA in all animals. $\boldsymbol{D}$, In the right BLA, fear conditioning activated $\mathrm{PV}^{+}$cells of NB males relative to controls, whereas this was not the case in LB males. Control LB males had significantly increased activation of $\mathrm{PV}^{+}$cells compared with NB males. Thus, LB-reared males in the fear group displayed reduced $\mathrm{Fos}^{+} / \mathrm{PV}^{+}$cell density compared with their NB counterparts. In NB fear-conditioned animals, males displayed increased $\mathrm{PV}^{+}$cell activity compared with females. $\boldsymbol{E}$, The density of activated PV ${ }^{+}$cells expressing PNN was not affected by bedding, sex, or treatment in the left BLA. $\boldsymbol{F}$, However, in the right BLA, fear conditioning increased the density of PNN around activated $\mathrm{PV}^{+}$cells. Three-way ANOVAs with bedding, sex, and treatment as between-subject factors were performed for each side and followed by simple effects tests to decompose significant interactions. Data are mean \pm SEM of $n=5$ animals/group (4 sections per amygdala side). ${ }^{*} p<0.05 .{ }^{* *} p<0.01 .{ }^{* * *} p<0.001$.

displayed increased density of PNNs, suggesting higher stabilization of synaptic inputs on these inhibitory interneurons. In contrast, the only effects of ELS noted in LB females were reduced neuron excitability and NMDAR subunit expression in the right BLA.

LB exposure enhanced LTP formation and input-output function in the BLA of juvenile males exclusively in the right, but not in the left, BLA, which was unaltered by LB conditions in either sex. This demonstrates that synaptic function in the BLA is already lateralized in juveniles and is sensitive to ELS. The amygdala is a lateralized structure with greater involvement of the right hemisphere in fear conditioning and pain processing in adult rodents and humans (Baker and Kim, 2004; Ji and Neugebauer, 2009; Vasa et al., 2011). Interestingly, laterality of LTP was observed in LB, but not NB, juvenile males, suggesting that early stress might accelerate the development of LTP lateralization. In NB females, LTP was lower in the left compared with the right $\mathrm{BLA}$, but $\mathrm{LB}$ exposure eliminated lateralization of LTP. Thus, negative emotional information encoding in LB male offspring is biased toward the right hemisphere as in adult rats (Adamec et al., 2005; Young and Williams, 2013).

Enhanced LTP formation in the adult male BLA after chronic stress participates in the potentiation of fear learning (Suvrathan et al., 2014); and in neonates, changes in synaptic plasticity are thought to promote the encoding of fearful stimuli (Thompson et al., 2008). The synaptic strengthening in LB juvenile males might lead to increased fear conditioning as observed previously in adult male, but not female, LB offspring (Guadagno et al., 2018a). The large sexual dimorphism for juvenile LTP in response to early LB conditions could be caused by ELS-induced mechanisms overlapping with the organizational period of brain sexual differentiation during the first week of life (Naninck et al., 2011). Sex differences in microglial cell number and activation contribute to brain masculinization in neonatal rodents (Lenz et al., 2013) and the sexually dimorphic maturation and development of neuronal circuits (Johnson and Kaffman, 2018). Microglia also regulate experiencedependent synaptic plasticity in the cortex of juvenile mice (Tremblay et al., 2010) and are sensitive to ELS exposure in the amygdala (Tynan et al., 2010). Thus, modified microglia function in the BLA following LB exposure might participate in sexually dimorphic synaptic changes.

Enhanced synaptic plasticity in stressed males might stem from several mechanisms. Our findings that BLA LTP was associated with an increase in fiber volley suggest that an increase in presynaptic axonal function may be responsible for the facilitated LTP in male LB offspring. Presynaptic mechanisms have been shown to contribute to the expression of some forms of LTP in the amygdala. In the LA, LTP of cortical inputs was related to a decrease in paired-pulse ratio, suggesting an increase in presynaptic function (Huang and Kandel, 1998; Tsvetkov et al., 2002; Humeau et al., 2003). Unlike the LA, the expression mechanisms of LA-BLA LTP that we have examined in this study are less well known. Rammes et al. (2001) have shown that, while intracellularly loading BLA neurons with a calcium chelator BAPTA did not inhibit LTP, LTP was abolished by a membrane-permeable BAPTA-AM, suggesting an involvement of presynaptic calcium in LTP formation. In our experiments, we also observed an increased fiber volley amplitude, suggestive of active presynaptic mechanisms, although this phenomenon occurred regardless of bedding condition. Although we cannot rule out that other presynaptic mechanisms participate in the increased LTP in the LB males, the increase in input-output function we observed in male LB offspring points to the involvement of enhanced postsynaptic function in stressed males. Further 
studies are needed to reveal the contribution of both presynaptic (paired-pulse ratio) and postsynaptic mechanisms (e.g., receptor trafficking) (Rumpel et al., 2005; Yu et al., 2008) to LTP changes caused by ELS.

In addition, increased intrinsic BLA pyramidal neuron excitability (Xu et al., 2005), as shown in adult males subjected to social isolation in adolescence (Rau et al., 2015), could be responsible for enhanced LTP in stressed males. Indeed, LB induced a trend for enhanced maximal depolarization rate and action potential amplitude in males, while the opposite effect was significant in females. This finding in LB males may result from increased expression of voltage-gated sodium channels, as shown in the ventral hippocampus for male offspring of low maternal care mothers (Nguyen et al., 2015). Changes in sodium-channel expression indirectly modify calcium conductance through NMDAR (Nguyen et al., 2015). Surprisingly, no changes in NMDAR subunits in the male BLA were detected, but we found a significant reduction in GluN1 protein levels in the right BLA in LB female offspring, which might have contributed to their reduced neuron excitability. Similar sex differences were observed for amygdala GluN1 levels in adult offspring exposed to stress in utero (Wang et al., 2015). It is unclear why none of the NMDAR subunits was modified in male offspring, given the large effect of LB to enhance LTP in the male right BLA. While NMDARs are crucial for the induction of LTP, other factors might also enhance LTP amplitude, such as the stronger $d V / d t$ and heightened neuron excitability we observed in LB males. A decrease in protein kinase $\beta$ II activity, a downstream cellular signaling molecule coupled to NMDARs (Orman and Stewart, 2007), increased spine density (Guadagno et al., 2018a), and/or a reduction of inhibitory control over pyramidal BLA neurons (Butler et al., 2018) could also be prevailing over NMDAR expression for regulating stress-related synaptic plasticity in the male BLA.

The significant reduction of GluA2 in the right BLA of juvenile male rats after early stress is similar to the reduced GluA2 expression observed in the adult BLA after chronic stress (Yi et al., 2017) and could contribute to a postsynaptic mechanism for LTP facilitation. Chronic stress has also been shown to enhance the inward rectification of AMPAR in the BLA (Kuniishi et al., 2020), suggesting an increase in AMPARs lacking the GluA2 subunit. Given the regulation of calcium permeability of AMPAR by the GluA2 subunit (for review, see Wright and Vissel, 2012), a reduction of GluA2 could enhance LTP formation via increasing calcium influx (Jia et al., 1996). Compared with the hippocampus with most glutamate synapses expressing GluA2, both ultrastructural and functional data support a lower GluA2 expression at BLA synapses in rats (Gryder et al., 2005). BLA plasticity is likely highly sensitive to the developmental reduction of GluA2 caused by ELS. Finally, reduction of GluA2 may weaken memory erasing mechanisms, such as depotentiation and extinction in the amygdala (Kim et al., 2007). Future studies are needed to examine the causal relationship between ELS- dependent reduction of GluA2 and changes in BLA-related synaptic plasticity and fear memory in juveniles.

As for adults (Spampanato et al., 2011), the proportion of $\mathrm{PV}^{+}$neurons represented $\sim 50 \%$ of the total GABAergic interneurons in the juvenile BLA regardless of sex, laterality, or early life conditions (Fig. 6). The density of PNNs and PV cells harboring PNNs in the juvenile BLA was significantly increased by LB on the right side and exclusively in males. This agrees with increased PNN density in the hippocampal CA1 (Riga et al., 2017) and mPFC (Pesarico et al., 2019) after chronic stress in adult males. Behaviorally, a greater number of neurons harboring PNNs might facilitate the storage of fearful memories (Banerjee et al., 2017), and it is proposed that PNNs serve as a physical barrier to protect neurons from oxidative damage (Cabungcal et al., 2013; Reichelt et al., 2019). The exacerbated neuronal activity in the right BLA of juvenile males suggests that those synapses require increased PNNs to buffer cations involved in neurotransmission (van 't Spijker and Kwok, 2017). Increased PNN numbers on the right side of the developing LB male BLA could enhance LTP formation, since enzymatic degradation of PNNs on all BLA cell types in adulthood decreases synaptic strengthening at LA inputs (Gogolla et al., 2009). While PNN density was increased especially on $\mathrm{PV}^{+}$and inhibitory cells in the right BLA of $\mathrm{LB}$ males, an overwhelming percentage of PNNs in the juvenile BLA were also likely on excitatory neurons, in line with what is observed in the medial and posterior regions of the adult BLA (Morikawa et al., 2017).

The significance of ELS and chronic stress-induced increases in PNNs on inhibitory function is not well understood and might be region-specific. In the cortex, PNNs enhance the excitability of $\mathrm{PV}^{+}$interneurons (Balmer, 2016), but it is unknown how they affect amygdala neurons. The increase in PNN induced by ELS might also be secondary to LB-induced accelerated maturation of BLA neurons in the male compared with the female (Arambula and McCarthy, 2020) or might occur at differential stages of sexually dimorphic corticolimbic neurodevelopment. Through their regulatory role on synaptic inputs, PNNs might be critical not only for the expression of fear during conditioning (in the present 
study), but also for fear extinction and fear memory (Gogolla et al., 2009) as there is evidence that ELS impairs fear extinction and memory in adult rodents (Lesuis et al., 2019). In addition to an effect on PNN, ELS might change the intracellular properties of $\mathrm{PV}^{+}$cells, rather than affecting their density, making them resistant to activation under emotional conditions. This is supported by our observation that, when juveniles were exposed to acute fear conditioning, the number of activated PV neurons in the right BLA was significantly reduced in LB compared with NB male rats (Fig. 8).

Fear conditioning significantly increased Fos responses in both sexes, but only in the right BLA. This is consistent with the lateralization of fear responsiveness in adult BLA neurons (Scicli et al., 2004). In males, fear conditioning stimulated $\mathrm{PV}^{+}$interneurons in the left BLA, in line with excitation of these cells during fear learning (Wolff et al., 2014). In the right $\mathrm{BLA}$, there was no further activation of $\mathrm{PV}^{+}$neurons by fear conditioning in LB males, possibly because their "basal" activity was considerably higher compared with $\mathrm{NB}$ males. In females, LB conditions did not significantly influence inhibitory neuron activity on either BLA side, suggesting that functional effects of early stress on BLA neuronal circuitry in females might predominantly be on glutamatergic cells, as reported in our study, or on other inhibitory neuron subtypes. Fos expression in the right BLA was lower in females compared with males, providing evidence for sexually dimorphic cellular activity in this region. This was also supported by our finding in NB fear-conditioned animals, where females displayed blunted $\mathrm{PV}^{+}$cell activity relative to males.

In contrast to what we observed in adult males (Guadagno et al., 2018a), there was no effect of LB on fear conditioning in male or female juveniles. A mild shock intensity was used $(0.6 \mathrm{~mA})$, yet freezing time often reached $\sim 90 \%$ of the trial duration, a potential ceiling level obscuring the effects of bedding and/or sex on fear behavior. Alternatively, it is possible that the magnitude of the cellular effects we report after LB exposure in males is insufficient to significantly alter behavioral outcomes in this developing circuit. We previously reported right-lateralized effects of LB exposure on BLA functional connectivity in preweaning male rats (Guadagno et al., 2018b). It is worth noting that these asymmetries were associated with increased fear behaviors in adulthood, suggesting that ELS-induced dysfunctions in the right, but not the left, BLA are primarily responsible for mediating enduring behavioral consequences. In addition to modifying the functional integrity of BLA connections, LB might also influence the interhemispheric crossing of anatomic connections, since adult (PND56) LB offspring display higher midline crossings than NB controls (Bolton et al., 2018). After puberty, stabilization of adult fear circuits might allow to fully reveal the behavioral effects of ELS exposure we and others have documented (Bolton et al., 2018; Guadagno et al., 2018a,b).

In conclusion, our results demonstrate that exposure to LB conditions leads to male-specific enhancements in synaptic plasticity and neuron excitability that are exclusively displayed in the right BLA. These functional changes were associated with accelerated development of PNNs, notably around PV cells, and impaired fear-induced inhibitory activity in the BLA. Females instead compensated for early adversity by reducing right amygdala neuron excitability and NMDAR subunit expression (Fig. 10). These data offer mechanistic insight into how ELS affects the juvenile BLA in a sex- and hemispheric-selective manner and highlights the critical role of the right amygdala and early steroid milieu in this process.

\section{References}

Adamec R, Shallow T, Burton P (2005) Anxiolytic and anxiogenic effects of kindling: role of baseline anxiety and anatomical location of the kindling electrode in response to kindling of the right and left basolateral amygdala. Behav Brain Res 159:73-88.

Arambula SE, McCarthy MM (2020) Neuroendocrine-immune crosstalk shapes sex-specific brain development. Endocrinology 161:bqaa055.

Aroniadou-Anderjaska V, Post RM, Rogawski MA, Li H (2001) Input-specific LTP and depotentiation in the basolateral amygdala. Neuroreport 12:635-640

Bagot RC, Tse YC, Nguyen HB, Wong AS, Meaney MJ, Wong TP (2012) Maternal care influences hippocampal N-methyl-D-aspartate receptor function and dynamic regulation by corticosterone in adulthood. Biol Psychiatry 72:491-498.

Baker KB, Kim JJ (2004) Amygdalar lateralization in fear conditioning: evidence for greater involvement of the right amygdala. Behav Neurosci $118: 15-23$.

Balmer TS (2016) Perineuronal nets enhance the excitability of fast-spiking neurons. eNeuro 3:ENEURO.0122-16.2016.

Banerjee SB, Gutzeit VA, Baman J, Aoued HS, Doshi NK, Liu RC, Ressler KJ (2017) Perineuronal nets in the adult sensory cortex are necessary for fear learning. Neuron 95:169-179.e163.

Bath KG, Manzano-Nieves G, Goodwill H (2016) Early life stress accelerates behavioral and neural maturation of the hippocampus in male mice. Horm Behav 82:64-71.

Bender RA, Zhou L, Vierk R, Brandt N, Keller A, Gee CE, Schäfer MK, Rune GM (2017) Sex-Dependent Regulation of Aromatase-Mediated Synaptic Plasticity in the Basolateral Amygdala. J Neurosci 37:1532-1545.

Berdel B, Moryś J (2000) Expression of calbindin-D28k and parvalbumin during development of rat's basolateral amygdaloid complex. Int J Dev Neurosci 18:501-513.

Bolton JL, Molet J, Ivy A, Baram TZ (2017) New insights into early-life stress and behavioral outcomes. Curr Opin Behav Sci 14:133-139.

Bolton JL, Molet J, Regev L, Chen Y, Rismanchi N, Haddad E, Yang DZ, Obenaus A, Baram TZ (2018) Anhedonia following early-life adversity involves aberrant interaction of reward and anxiety circuits and is reversed by partial silencing of amygdala corticotropin-releasing hormone gene. Biol Psychiatry 83:137-147.

Bonapersona V, Kentrop J, Van Lissa CJ, van der Veen R, Joëls M, Sarabdjitsingh RA (2019) The behavioral phenotype of early life adversity: a 3-level meta-analysis of rodent studies. Neurosci Biobehav Rev 102:299-307.

Bullitt E (1990) Expression of c-fos-like protein as a marker for neuronal activity following noxious stimulation in the rat. J Comp Neurol 296:517530.

Butler RK, Oliver EM, Fadel JR, Wilson MA (2018) Hemispheric differences in the number of parvalbumin-positive neurons in subdivisions of the rat basolateral amygdala complex. Brain Res 1678:214-219.

Cabungcal JH, Steullet P, Morishita H, Kraftsik R, Cuenod M, Hensch TK, Do KQ (2013) Perineuronal nets protect fast-spiking interneurons against oxidative stress. Proc Natl Acad Sci USA 110:9130-9135.

Dalton GL, Wu DC, Wang YT, Floresco SB, Phillips AG (2012) NMDA GluN2A and GluN2B receptors play separate roles in the induction of LTP and LTD in the amygdala and in the acquisition and extinction of conditioned fear. Neuropharmacology 62:797-806.

Delaney AJ, Sedlak PL, Autuori E, Power JM, Sah P (2013) Synaptic NMDA receptors in basolateral amygdala principal neurons are triheteromeric proteins: physiological role of GluN2B subunits. J Neurophysiol 109: 1391-1402.

Derks NA, Krugers HJ, Hoogenraad CC, Joels M, Sarabdjitsingh RA (2016) Effects of early life stress on synaptic plasticity in the developing hippocampus of male and female rats. PLoS One 11:e0164551.

Diering GH, Huganir RL (2018) The AMPA receptor code of synaptic plasticity. Neuron 100:314-329.

Ehrlich DE, Ryan SJ, Rainnie DG (2012) Postnatal development of electrophysiological properties of principal neurons in the rat basolateral amygdala. J Physiol 590:4819-4838. 
Gogolla N, Caroni P, Luthi A, Herry C (2009) Perineuronal nets protect fear memories from erasure. Science 325:1258-1261.

Goodwill HL, Manzano-Nieves G, Gallo M, Lee HI, Oyerinde E, Serre T, Bath KG (2019) Early life stress leads to sex differences in development of depressive-like outcomes in a mouse model. Neuropsychopharmacology 44:711-720.

Gryder DS, Castaneda DC, Rogawski MA (2005) Evidence for low GluR2 AMPA receptor subunit expression at synapses in the rat basolateral amygdala. J Neurochem 94:1728-1738.

Guadagno A, Wong TP, Walker CD (2018a) Morphological and functional changes in the preweaning basolateral amygdala induced by early chronic stress associate with anxiety and fear behavior in adult male, but not female rats. Prog Neuropsychopharmacol Biol Psychiatry 81:25-37.

Guadagno A, Kang MS, Devenyi GA, Mathieu AP, Rosa-Neto P, Chakravarty M, Walker CD (2018b) Reduced resting-state functional connectivity of the basolateral amygdala to the medial prefrontal cortex in preweaning rats exposed to chronic early-life stress. Brain Struct Funct 223:3711-3729.

Hetzel A, Rosenkranz JA (2014) Distinct effects of repeated restraint stress on basolateral amygdala neuronal membrane properties in resilient adolescent and adult rats. Neuropsychopharmacology 39:2114-2130.

Huang YY, Kandel ER (1998) Postsynaptic induction and PKA-dependent expression of LTP in the lateral amygdala. Neuron 21:169-178.

Humeau Y, Shaban H, Bissiere S, Luthi A (2003) Presynaptic induction of heterosynaptic associative plasticity in the mammalian brain. Nature 426:841-845.

Ji G, Neugebauer V (2009) Hemispheric lateralization of pain processing by amygdala neurons. J Neurophysiol 102:2253-2264.

Jia Z, Agopyan N, Miu P, Xiong Z, Henderson J, Gerlai R, Taverna FA, Velumian A, MacDonald J, Carlen P, Abramow-Newerly W, Roder J (1996) Enhanced LTP in mice deficient in the AMPA receptor GluR2. Neuron 17:945-956.

Johnson FK, Kaffman A (2018) Early life stress perturbs the function of microglia in the developing rodent brain: new insights and future challenges. Brain Behav Immun 69:18-27.

Jovanovic T, Nylocks KM, Gamwell KL (2013) Translational neuroscience measures of fear conditioning across development: applications to highrisk children and adolescents. Biol Mood Anxiety Disord 3:17.

Kim J, Lee S, Park K, Hong I, Song B, Son G, Park H, Kim WR, Park E, Choe HK, Kim H, Lee C, Sun W, Kim K, Shin KS, Choi S (2007) Amygdala depotentiation and fear extinction. Proc Natl Acad Sci USA 104:2095520960.

Krugers HJ, Arp JM, Xiong H, Kanatsou S, Lesuis SL, Korosi A, Joels M, Lucassen PJ (2017) Early life adversity: lasting consequences for emotional learning. Neurobiol Stress 6:14-21.

Kuniishi H, Yamada D, Wada K, Yamada M, Sekiguchi M (2020) Stress induces insertion of calcium-permeable AMPA receptors in the OFCBLA synapse and modulates emotional behaviours in mice. Transl Psychiatry 10:154.

Lenroot RK, Gogtay N, Greenstein DK, Wells EM, Wallace GL, Clasen LS, Blumenthal JD, Lerch J, Zijdenbos AP, Evans AC, Thompson PM, Giedd JN (2007) Sexual dimorphism of brain developmental trajectories during childhood and adolescence. Neuroimage 36:1065-1073.

Lenz KM, Nugent BM, Haliyur R, McCarthy MM (2013) Microglia are essential to masculinization of brain and behavior. J Neurosci 33:2761-2772.

Lesuis SL, Lucassen PJ, Krugers HJ (2019) Early life stress impairs fear memory and synaptic plasticity: a potential role for GluN2B. Neuropharmacology 149:195-203.

Lopez de Armentia M, Sah P (2003) Development and subunit composition of synaptic NMDA receptors in the amygdala: NR2B synapses in the adult central amygdala. J Neurosci 23:6876-6883.

Malter Cohen M, Jing D, Yang RR, Tottenham N, Lee FS, Casey BJ (2013) Early-life stress has persistent effects on amygdala function and development in mice and humans. Proc Natl Acad Sci USA 110:18274-18278.

McLaughlin RJ, Verlezza S, Gray JM, Hill MN, Walker CD (2016) Inhibition of anandamide hydrolysis dampens the neuroendocrine response to stress in neonatal rats subjected to suboptimal rearing conditions. Stress 19:114-124.

Miller LA, Heroux NA, Stanton ME (2020) NMDA receptors and the ontogeny of post-shock and retention freezing during contextual fear conditioning. Dev Psychobiol 62:380-385.
Molet J, Maras PM, Avishai-Eliner S, Baram TZ (2014) Naturalistic rodent models of chronic early-life stress. Dev Psychobiol 56:1675-1688

Morikawa S, Ikegaya Y, Narita M, Tamura H (2017) Activation of perineuronal net-expressing excitatory neurons during associative memory encoding and retrieval. Sci Rep 7:46024.

Moriyama C, Galic MA, Mychasiuk R, Pittman QJ, Perrot TS, Currie RW, Esser MJ (2013) Prenatal transport stress, postnatal maternal behavior, and offspring sex differentially affect seizure susceptibility in young rats. Epilepsy Behav 29:19-27.

Muller T, Albrecht D, Gebhardt C (2009) Both NR2A and NR2B subunits of the NMDA receptor are critical for long-term potentiation and long-term depression in the lateral amygdala of horizontal slices of adult mice. Learn Mem 16:395-405.

Naninck EF, Lucassen PJ, Bakker J (2011) Sex differences in adolescent depression: do sex hormones determine vulnerability? J Neuroendocrinol 23:383-392.

Nguyen HB, Bagot RC, Diorio J, Wong TP, Meaney MJ (2015) Maternal care differentially affects neuronal excitability and synaptic plasticity in the dorsal and ventral hippocampus. Neuropsychopharmacology 40:15901599.

Opendak M, Zanca RM, Anane E, Serrano PA, Sullivan RM (2018) Developmental transitions in amygdala PKC isoforms and AMPA receptor expression associated with threat memory in infant rats. Sci Rep 8:14679.

Orman R, Stewart M (2007) Hemispheric differences in protein kinase C $\beta$ II levels in the rat amygdala: baseline asymmetry and lateralized changes associated with cue and context in a classical fear conditioning paradigm. Neuroscience 144:797-807.

Pape HC, Pare D (2010) Plastic synaptic networks of the amygdala for the acquisition, expression, and extinction of conditioned fear. Physiol Rev 90:419-463.

Paxinos G, Watson C (2005) The rat brain in stereotaxic coordinates, Ed 5. Amsterdam: Elsevier.

Pesarico AP, Bueno-Fernandez C, Guirado R, Gomez-Climent MA, Curto Y, Carceller H, Nacher J (2019) Chronic stress modulates interneuronal plasticity: effects on PSA-NCAM and perineuronal nets in cortical and extracortical regions. Front Cell Neurosci 13:197.

Rammes G, Eder M, Dodt HU, Kochs E, Zieglgansberger W (2001) Longterm depression in the basolateral amygdala of the mouse involves the activation of interneurons. Neuroscience 107:85-97.

Rau AR, Chappell AM, Butler TR, Ariwodola OJ, Weiner JL (2015) Increased basolateral amygdala pyramidal cell excitability may contribute to the anxiogenic phenotype induced by chronic early-life stress. J Neurosci 35:9730-9740.

Reichelt AC, Hare DJ, Bussey TJ, Saksida LM (2019) Perineuronal nets: plasticity, protection, and therapeutic potential. Trends Neurosci 42:458-470.

Riga D, Kramvis I, Koskinen MK, van Bokhoven P, van der Harst JE, Heistek TS, Timmerman A, van Nierop P, van der Schors RC, Pieneman AW, de Weger A, van Mourik Y, Schoffelmeer AN, Mansvelder HD, Meredith RM, Hoogendijk WJ, Smit AB, Spijker S (2017) Hippocampal extracellular matrix alterations contribute to cognitive impairment associated with a chronic depressive-like state in rats. Sci Transl Med 9:eaai8753.

Rumpel S, LeDoux J, Zador A, Malinow R (2005) Postsynaptic receptor trafficking underlying a form of associative learning. Science 308:83-88.

Santiago AN, Lim KY, Opendak M, Sullivan RM, Aoki C (2018) Early life trauma increases threat response of peri-weaning rats, reduction of axosomatic synapses formed by parvalbumin cells and perineuronal net in the basolateral nucleus of amygdala. J Comp Neurol 526:2647-2664.

Scicli AP, Petrovich GD, Swanson LW, Thompson RF (2004) Contextual fear conditioning is associated with lateralized expression of the immediate early gene c-fos in the central and basolateral amygdalar nuclei. Behav Neurosci 118:5-14.

Seeger G, Luth HJ, Winkelmann E, Brauer K (1996) Distribution patterns of Wisteria floribunda agglutinin binding sites and parvalbumin-immunoreactive neurons in the human visual cortex: a double-labelling study. J Hirnforsch 37:351-366.

Slaker ML, Harkness JH, Sorg BA (2016) A standardized and automated method of perineuronal net analysis using Wisteria floribunda agglutinin staining intensity. IBRO Rep 1:54-60.

Spampanato J, Polepalli J, Sah P (2011) Interneurons in the basolateral amygdala. Neuropharmacology 60:765-773. 
Stevenson CW, Spicer CH, Mason R, Marsden CA (2009) Early life programming of fear conditioning and extinction in adult male rats. Behav Brain Res 205:505-510.

Suvrathan A, Bennur S, Ghosh S, Tomar A, Anilkumar S, Chattarji S (2014) Stress enhances fear by forming new synapses with greater capacity for long-term potentiation in the amygdala. Philos Trans R Soc Lond B Biol Sci 369:20130151.

Takesian AE, Hensch TK (2013) Balancing plasticity/stability across brain development. Prog Brain Res 207:3-34.

Thompson JV, Sullivan RM, Wilson DA (2008) Developmental emergence of fear learning corresponds with changes in amygdala synaptic plasticity. Brain Res 1200:58-65.

Tremblay ME, Lowery RL, Majewska AK (2010) Microglial interactions with synapses are modulated by visual experience. PLoS Biol 8:e1000527.

Tsvetkov E, Carlezon WA, Benes FM, Kandel ER, Bolshakov VY (2002) Fear conditioning occludes LTP-induced presynaptic enhancement of synaptic transmission in the cortical pathway to the lateral amygdala. Neuron 34:289-300.

Tynan RJ, Naicker S, Hinwood M, Nalivaiko E, Buller KM, Pow DV, Day TA, Walker FR (2010) Chronic stress alters the density and morphology of microglia in a subset of stress-responsive brain regions. Brain Behav Immun 24:1058-1068.

van 't Spijker HM, Kwok JC (2017) A sweet talk: the molecular systems of perineuronal nets in controlling neuronal communication. Front Integr Neurosci 11:33.

Vasa RA, Pine DS, Thorn JM, Nelson TE, Spinelli S, Nelson E, Maheu FS, Ernst M, Bruck M, Mostofsky SH (2011) Enhanced right amygdala activity in adolescents during encoding of positively valenced pictures. Dev Cogn Neurosci 1:88-99.

Walker CD, Bath KG, Joels M, Korosi A, Larauche M, Lucassen PJ, Morris MJ, Raineki C, Roth TL, Sullivan RM, Tache Y, Baram TZ (2017)
Chronic early life stress induced by limited bedding and nesting (LBN) material in rodents: critical considerations of methodology, outcomes and translational potential. Stress 20:421-448.

Wang Y, Ma Y, Hu J, Cheng W, Jiang H, Zhang X, Li M, Ren J, Li X (2015) Prenatal chronic mild stress induces depression-like behavior and sexspecific changes in regional glutamate receptor expression patterns in adult rats. Neuroscience 301:363-374.

Wolff SB, Grundemann J, Tovote P, Krabbe S, Jacobson GA, Muller C, Herry C, Ehrlich I, Friedrich RW, Letzkus JJ, Luthi A (2014) Amygdala interneuron subtypes control fear learning through disinhibition. Nature 509:453-458.

Woodruff AR, Sah P (2007a) Inhibition and synchronization of basal amygdala principal neuron spiking by parvalbumin-positive interneurons. J Neurophysiol 98:2956-2961.

Woodruff AR, Sah P (2007b) Networks of parvalbumin-positive interneurons in the basolateral amygdala. J Neurosci 27:553-563.

Wright A, Vissel B (2012) The essential role of AMPA receptor GluR2 subunit RNA editing in the normal and diseased brain. Front Mol Neurosci 5:34.

Xu J, Kang N, Jiang L, Nedergaard M, Kang J (2005) Activity-dependent long-term potentiation of intrinsic excitability in hippocampal CA1 pyramidal neurons. J Neurosci 25:1750-1760.

Yi ES, Oh S, Lee JK, Leem YH (2017) Chronic stress-induced dendritic reorganization and abundance of synaptosomal PKA-dependent CP-AMPA receptor in the basolateral amygdala in a mouse model of depression. Biochem Biophys Res Commun 486:671-678.

Young EJ, Williams CL (2013) Differential activation of amygdala Arc expression by positive and negatively valenced emotional learning conditions. Front Behav Neurosci 7:191.

Yu SY, Wu DC, Liu L, Ge Y, Wang YT (2008) Role of AMPA receptor trafficking in NMDA receptor-dependent synaptic plasticity in the rat lateral amygdala. J Neurochem 106:889-899. 